Article

\title{
Development of an Analyzing and Tuning Methodology for the CNC Parameters Based on Machining Performance
}

\author{
Ben-Fong $\mathrm{Yu} * \mathbb{D}$ and Jenq-Shyong Chen \\ Department of Mechanical Engineering, National Chung Hsing University, 40227 Taichung, Taiwan; \\ MichaelChen@dragon.nchu.edu.tw \\ * Correspondence: headway987@gmail.com; Tel.: +886-4-2284-0165 (ext. 4032)
}

Received: 14 March 2020; Accepted: 11 April 2020; Published: 14 April 2020

\begin{abstract}
This paper proposes the development of a tuning methodology which can set the proper values of the Computer Numerical Control $(\mathrm{CNC})$ parameters to achieve the required machining performance. For the conventional operators of machine tools, the CNC parameters were hard to be adjusted to optimal settings, which was a complicated and time-consuming task. To save time in finding optimal CNC parameters, the objective of this research was to develop a practical methodology to tune the CNC parameters effectively for easy implementation in the commercial CNC controller. Firstly, the effect of the CNC parameters in the CNC controller on the tool-path planning was analyzed via experiments. The machining performance was defined in the high-speed (HS) mode, the high-accuracy (HP) mode, and the high-surface-quality (HQ) mode, according to the dynamic errors of several specified paths. Due to the CNC parameters that have a particularly critical effect on the dynamic errors, the relationship between the CNC parameters and the dynamic errors was validated by the measured data. Finally, the tuning procedure defined the anticipated dynamic errors for the three machining modes with the actual machine. The CNC parameters will correspond with anticipated dynamics errors based on several specified paths. The experimental results showed that the HS mode was the fastest to complete the path, and the completion time of the HP and HQ modes were increased by $37 \%$ and $6 \%$, respectively. The HP mode had the smallest dynamic errors than other modes, and the dynamic errors of the HS and HQ modes are increased by $66 \%$ and $16 \%$. In the HQ mode, the motion oscillation was reduce significantly, and the tracking error of the HS and HP modes were increased by $85 \%$ and $28 \%$. The advantage of the methodology is that it simplifies set-up steps of the $\mathrm{CNC}$ parameters, making it suitable for practical machine applications.
\end{abstract}

Keywords: CNC parameters; machining mode; high speed; high accuracy; high surface quality

\section{Introduction}

There are many kinds of products produced with Computer Numerical Control (CNC) machine tools. According to the workpiece weight, geometric shape, material, tools, and cutting conditions, the operator needs to estimate the proper manufacturing processes, so the machining requirements will not be the same. Some products require an extremely smooth surface, such as plastic injection molds, while others require high geometrical accuracy and little tolerance, such as precision machine elements (cf., gears), and still others require high cutting efficiency (i.e., material removal rate) and allow larger tolerance, such as the aluminum brackets for bicycle or aerospace. This situation is why machine tools have focused on how to accomplish high-surface-quality (HQ), high-accuracy (HP) and high-speed (HS) machining. Most of the commercial CNC machine tools are equipped with a standard set of CNC parameters, which are not changed according to the different machining demands. The standard set of 
$\mathrm{CNC}$ parameters of machine tools are created by their manufacturers. However, the tuning of CNC parameters has to require a lot of domain knowledge, including the most basic theories, such as statics, dynamics, kinematics, mechanism, motion control, etc. More advanced knowledge also includes the quality of Computer Aided Manufacturing (CAM), interpolation, machine performance, tool geometry, cutting conditions, etc. That is why the machine operators cannot easily tune the CNC parameters to match their product for relevant machining requirements. Figure 1 shows the architecture of feed motion processing sequence in the commercial CNC machine tools in this study. Firstly, the CAM model generates the corresponding Numerical Control (NC) code. The position command of the NC code $\left(S_{g}\right)$ would be interpreted by the $\mathrm{CNC}$ controller for tool-path planning in interpolator, and that generates the motion trajectory based on the $\mathrm{CNC}$ parameters. Therefore, the CNC parameters include the velocity, acceleration, and jerk for their path statements, such as straight, corner, and arc paths. An algorithm on the tool-path planning produced the kinematic profiles of their relevant position, velocity, acceleration, and jerk based on NC code and CNC parameters. According to the kinematic profiles, each servo axis would move along the trajectory motion that was defined as position command $\left(S_{c}\right)$. The $S_{c}$ drives the feed drive system of the machine tools via servo loop. The feedback signal was defined as the actual position $\left(S_{a}\right)$ for the feed drive system in the machine tools. Finally, the real workpiece would be produced based on the tool path, tool, material, and cutting conditions. The loop of the blue arrow in Figure 1 has been widely used in all machine tools.

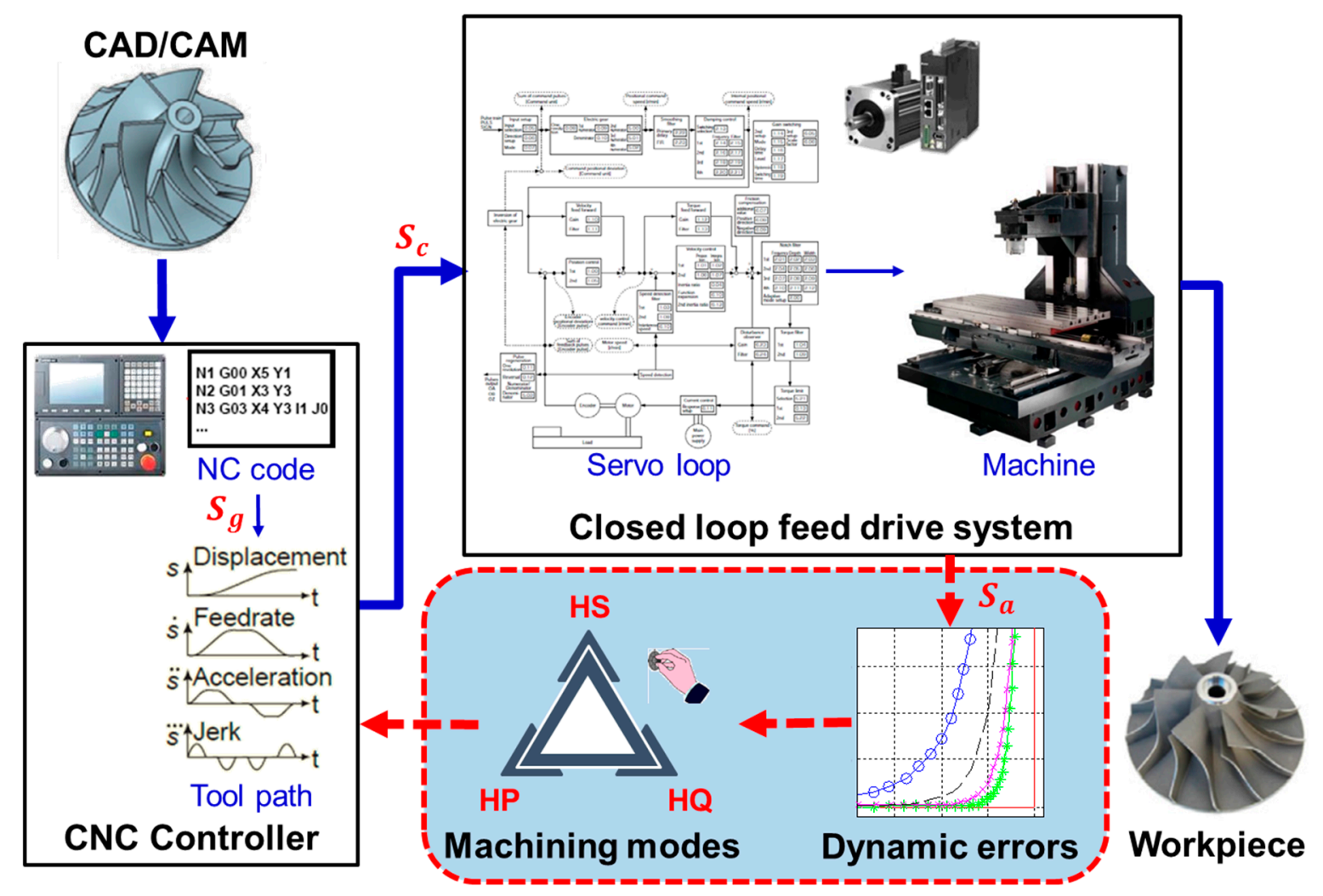

Figure 1. The goal architecture of the processing sequence in this study.

The goal of this study was to analyze the relationships among machining modes, CNC parameters, and dynamic errors, followed by developing the tuning procedure which can tune the proper values of the CNC parameters to match the selected machining mode; it is shown on the red dot frame in Figure 1. Firstly, an analysis of the CNC parameters based on algorithm of tool-path planning in the conventional controller, and the principle of tool-path planning was organized. It proposed the dynamic errors chain that we have to observe in actual machine tools. In this paper, dynamic errors signify the deviation between the position of the NC code and the actual position of the feed drive 
system. It contains two parts: One part is the difference between the $S_{g}$ and $S_{c}$, another part is the difference between the $S_{c}$ and $S_{a}$. Secondly, we experimented on the machining modes with different $\mathrm{CNC}$ parameters and collected data. It presents a tuning criteria for the three machining modes and CNC parameters. Finally, this study adjusted the CNC parameters and analyzed the experimental results with an actual machine to develop the tuning methodology for machining modes. It proposes the tuning methodology and procedure for the CNC parameters based on machining requirements.

A number of studies have analyzed the effects of the tool-path planning to follow the desired contours, and jerk control strategies have been proposed [1-4]. According to the path distance and feedrate of the NC code, the form of the acceleration profile must first be defined by the presetting of jerk and acceleration for $\mathrm{CNC}$ parameters; the acceleration profile of the triangle or trapezoid was planned. Some literature introduced the advanced method for interpolation, such as Non-Uniform Rational B-Splines (NURBS) and Bazier [5,6]. Sencer et al. [7] literature presented the algorithm with learning for NC code re-established. Therefore, the objective of the tool-path planning is to ensure the feedrate can be smoothed for precision results as required. Tapie et al. [8] proposed the circular tests for high speed machining, and proposed the limit values of jerk, acceleration, and circular velocity. However, the tool path is not only a circular path, but also contains straight and corner paths. This study did not discuss the other CNC parameters. Pateloup et al. [9] presented the corner optimization. However, it proposed the corner with arc path for pocket machining. In general, the corner path consists of two short lines, and the limit of corner velocity avoids the vibration after the corner motion. This study did not obtain the corner velocity of CNC parameters.

Andolfatto et al. [10] presented the dynamic errors at the tool center point, and included the contour error caused by a closed loop feed drive system and actual error from the machine structure that defined the feedback position to relate tool center point. However, this study did not discuss the error caused by CNC parameters. Lee et al. [11] also established a servo parameter tuning method based on the corner error. The experimental results based on the corner error measurements showed that the proposed tuning methods are very effective in improving the corner accuracy of a three-axis high-speed CNC machine tool. Parenti et al. [12] proposed the acceleration spectrum of the acceleration profiles which exert significant effects on the behavior of the dynamic errors in the $\mathrm{CNC}$ machine tools at the tool center point. Bringmann et al. [13] introduced a measurement device based on the "R-test" for measuring displacements in the three linear degrees of freedom, and for evaluating the dynamic errors of the machine at the tool center point. The CNC parameters, such as jerk and acceleration limits, can be set to obtain the required dynamic path accuracy. However, the proposed tuning method was proven only for the HP mode, and not for the HQ or HS mode. Li et al. [14] presented the different feedrate effect on the dynamic errors of the feed drive system. This proposal was useful for HQ mode, but this study did not have any solutions to tune the other modes.

Some studies have analyzed the influence of motion errors for the machining performance. Some scholars focus on the dynamic errors caused by tool geometrics [15-17]. It is dependent on a larger machine and the dynamic errors' source on machine structure. Mia et al. [18] presented intelligent optimization of hard-turning parameters. This paper proposed the evolutionary algorithms for cutting conditions. Their dynamic errors adjust method was to change the cutting conditions. The main disadvantage is that the error between the measuring tool center point and the geometry of NC code must be considered. This is not a trivial task for the machine's operator. Li et al. $[19,20]$ introduced the ambient environmental temperature effect on the positioning accuracy of moving carrier on machine tools. Therefore, the carrier embedded cooling channels to achieve thermal error suppression, and the machine tools were operated in an air conditioning chamber in which the temperature could be controlled. However, the variation of accuracy caused by thermal deformation of machine tools comes from the long-term machining. Actually, there are not any CNC parameters to solve the problem of thermal displacement.

Several works developed the virtual machine tool technology which predicts the contour error of the closed loop feed drive system of the CNC machine tools [21-26]. However, the virtual machine 
tool technology proposed by these previous works involved a mechatronic model which integrated the servo driver, mechanics of the feed drive mechanism, and the dynamics of the machine structures. Although the effects on the dynamic errors after changing the CNC and servo parameters have been studied, they did not establish or propose any tuning algorithm to switch the machining performance between HS, HP, and HQ modes.

Conventional controllers have been provided with the functions of the HS, HP, and HQ modes in the CNC machine tools; they are predominantly used in trajectory generation $[27,28]$. When the user selects a machining mode, the controller has to process feedrate with the NC blocks. In order to achieve the machining strategy, the control method has to match the tolerance value of the path contour via a relevant NC program. However, the algorithm of different machining modes isn't included in the feed drive system of real CNC machine tools; the function is merely processed in the interpolation of the controller.

This paper presents a tuning methodology for the CNC parameters, and, hence, matches the machine's dynamic errors according to the selection of machining modes which are set by the mixed combination of three machining modes: The HS mode, HP mode, and HQ mode. The relationship between CNC parameters and dynamic errors is defined in Section 2. Section 3 uses simple paths to test the tuning criteria of the $\mathrm{CNC}$ parameters and different machining requirements. The tuning methodology and procedure of the CNC parameters based on machining modes were implemented in this section. In Section 5, the CNC parameters were estimated based on the relevant machining modes for experimental validation. Finally, the conclusion is presented in Section 6.

\section{The Definition of the CNC Parameters and Dynamic Errors}

\subsection{Tool-Path Planning in the CNC Controller}

The function of the interpolator is to generate the velocity profile of the tool path, so the interpolator needs to provide smooth velocity change during the contour machining via a multi-axis machine tool. The tool-path planning algorithm maintains a smooth velocity transition during the high-speed feed motion. Most commercial CNC controllers use S-curve velocity profile along with the function of jerk control. According to the specific feedrate and displacement from the NC code, the kinematic profiles (velocity) are generated by the interpolator in the CNC controller with the CNC parameters (jerk, acceleration, and time constant of the acceleration/deceleration (Acc/Dec)).

Figure 2 shows the typical trapezoidal acceleration profile. For feed motion along the tool path, acceleration profiles are linear, velocity profiles are parabolic, and position profiles are cubic for regions $1,3,5$, and 7 where time constant of Acc/Dec with constant jerk occurs. Acceleration values are constant and jerk is zero for regions 2 and 6, where velocity profiles are linear and position profiles are parabolic. In region 4 , jerk and acceleration values are zero, velocity is constant, and position is linear. If the feed motion has the greatest acceleration, the acceleration profile does not have the regions 2 and 6 . When the triangular acceleration profile has been generated, the result is no constant acceleration, but it has a short acceleration peak. While this profile is useful to reduce machining time, it has very high requirements on the performance of the machine. Finally, the result of the tool-path planning is divided into the position command of each feed axis to enter the servo loop, and the motor that drives each feed axis reaches the position required for the workpiece shape.

Actually, the tool-path geometry not only consists of a straight path, but also includes circular and curved paths generated from many short lines. The general purpose machine tool consists of three mutually perpendicular linear axes, and the multi-axis synchronous motion makes the tool-path process a complex shape. Figure 3 shows the tool path with complex shape. It consists of many short lines. When the $\mathrm{X}$ and $\mathrm{Y}$ axes are in synchronous motion for the tool path, the path velocity will be reduced to distribute the $X$-axis velocity $\left(V_{x}\right)$ and $Y$-axis velocity $\left(V_{y}\right)$. The $P_{1}$ and $P_{2}$ are the corner motion. The feedrate must be decreased at $t_{\mathrm{P} 1}$ and $t_{\mathrm{P} 2}$ (as shown in Figure 3). One of the CNC parameters is to set a corner velocity $\left(V_{c}\right)$ for the tool-path planning; the $V_{c}$ is composed of the $V_{x}$ and 
$V_{y}$. The purpose is to define the time point at which the $V_{y}$ starts to increase velocity when the $V_{x}$ has decelerated to the $V_{c}$.

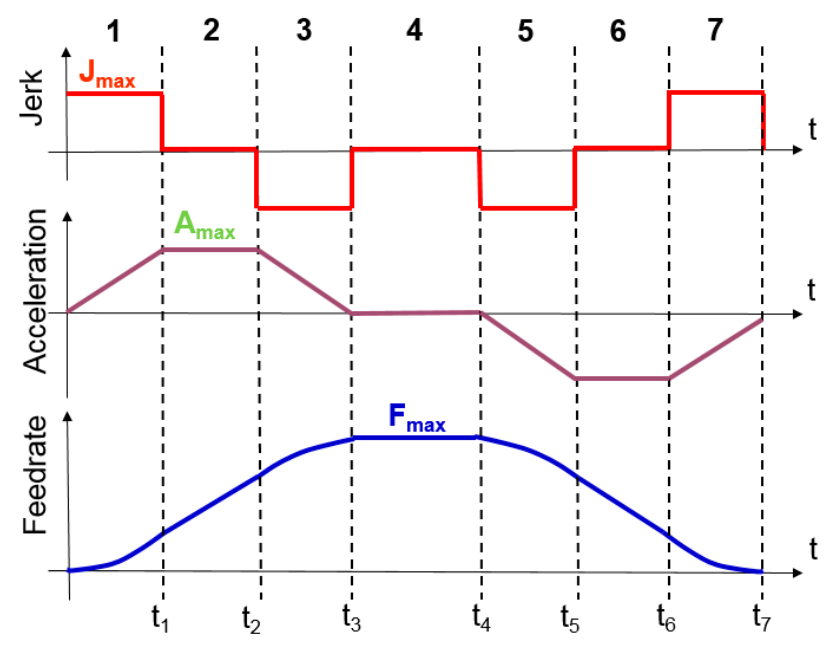

Figure 2. Typical trapezoidal acceleration profile.
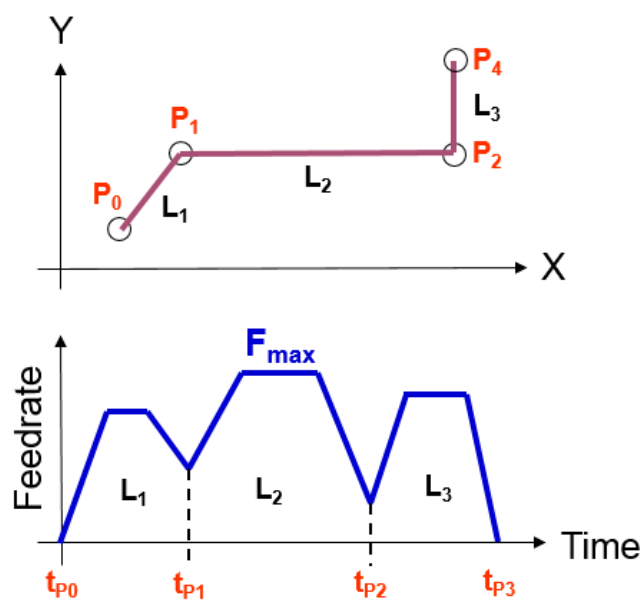

Figure 3. The velocity profile with the complex shape.

The NC code is circular with the radius $(R)$, and the circular path is composed of the $X$-axis and the $Y$-axis. In fact, the path velocity $\left(V_{p}\right)$ has to be consistent, while the $V_{x}$ and $V_{y}$ are changing constantly, and each axis is constantly accelerating and decelerating at the same time. Tapie et al. [8] showed that the velocity profiles are similar to the sine wave during the feed motion. There are two kinds of CNC parameters to limit the velocity of the circular path for the interpolator in a commercial controller. One is the arc velocity $\left(V_{a}\right)$ and the other is centripetal acceleration $\left(A_{c}\right)$. The feedrate of NC code $\left(V_{f}\right)$ is similar to the $V_{p}$, but the $V_{f}$ is only used in the velocity of the circular path for the tool-path planning. The relationship between the centripetal acceleration and the arc velocity is expressed as:

$$
A_{p}=\left(V_{f}\right)^{2} / R
$$

When $V_{f}$ is larger than the feed motion, the greater centripetal acceleration is excited, causing the error between the circular path and the ideal path at the same time.

The flow chart of the tool-path planning was organized as shown in Figure 4. According to the path geometry and feedrate of the NC code, the form of the acceleration profile must first be defined. The profile of the triangle or trapezoid was planned by presetting jerk $\left(J_{p}\right)$, acceleration $\left(A_{p}\right)$, and time constant of the Acc/Dec $\left(T_{p}\right)$. These values can be preset by the CNC parameters of the controller. The actual acceleration $\left(A_{p}^{\prime}\right)$ will be defined by the tool-path planning. It includes the corner velocity 
$\left(V_{c}\right)$, arc velocity $\left(V_{a}\right)$, and smoothing time constant $\left(T_{a}\right)$ for the velocity profile with path velocity $\left(V_{p}\right)$, and, finally, the completed position command required for each axis $\left(S_{c x}, S_{c y}, S_{c z}\right)$. The most important function of the controller's interpolator is making the velocity profiles of each axis as smooth as possible to avoid tool-path drastic speed changes. The drastic speed changes would produce force, causing machine deformation or oscillation during the machining process, which would affect the accuracy of the workpiece and surface. This study adjusted the parameters and analyzed the experimental results with an actual machine to develop the tuning methodology for machining modes.

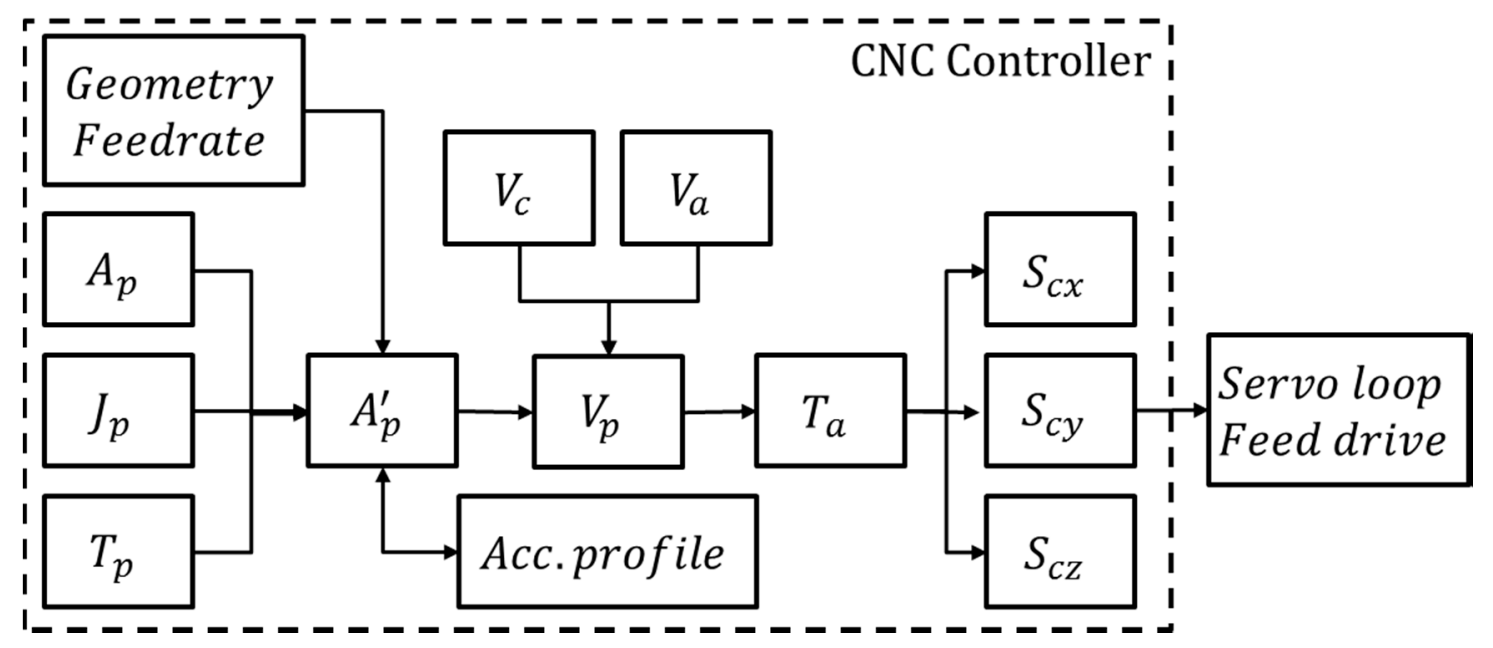

Figure 4. The principle of the tool-path planning in interpolator.

\subsection{The Dynamic Errors' Chain Corresponding to the Trajectory Generation}

Dynamic errors signify the deviation between the path of the NC code and the actual path. They contain the error from the NC code after interpolation in the controller that is a command error. In Figure 1, the command error $\left(\varepsilon_{1}\right)$ is the deviation between the original command from the NC code $\left(S_{g}\right)$ and the position command $\left(S_{c}\right)$ through the interpolator, expressed as:

$$
\text { Command error }=\varepsilon_{1}=S_{g}-S_{c} \text {. }
$$

The command error represents the influence of the CNC parameters in the tool-path planning.

Contour error $\left(\varepsilon_{2}\right)$ is another dynamic error, caused by the dynamic characteristics of the servo loop and feed drive system. The corresponding contour error is the deviation between the position command $\left(S_{c}\right)$ and actual position $\left(S_{a}\right)$ expressed as:

$$
\text { Contour error }=\varepsilon_{2}=S_{c}-S_{a}
$$

where $S_{c}$ and $S_{a}$ are position command and actual position, respectively. Numerous studies $[4,11,17]$ used the contour error to analyze the performance of machine tools. The phenomenon of servo delay causes position error, called tracking error, on a single axis, and is named as contour error if the path was simultaneously moving by multi-axis. The dynamic errors $\left(\varepsilon_{3}\right)$ include $\varepsilon_{1}$ and $\varepsilon_{2}$, introduced as:

$$
\text { Dynamic errors }=\varepsilon_{3}=\varepsilon_{1}+\varepsilon_{2}=S_{g}-S_{a}
$$

The $\varepsilon_{1}$ was caused by the interpolator in tool-path planning, while the $\varepsilon_{2}$ was caused by the closed loop feed drive system of the machine. Figure 5 shows the dynamic errors chain with $\varepsilon_{1}$ and $\varepsilon_{2}$ for the corner path and the circular path, respectively. In the following description, we focused on the development of the $\mathrm{HS} / \mathrm{HP} / \mathrm{HQ}$ mode by observing the dynamic errors during the axis movement. 

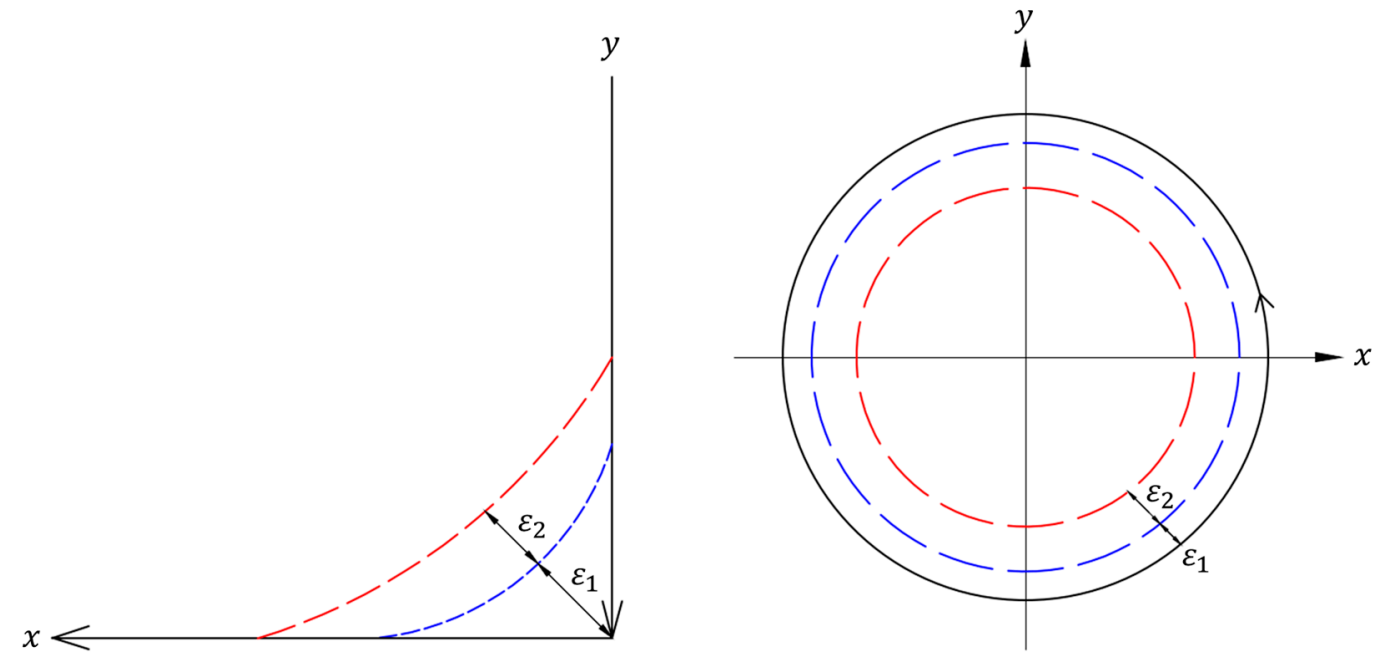

Figure 5. The dynamic errors in corner path and circular paths.

The tool-path planning purpose is to control the path velocity and slow down the velocity change of each axis when the machine moves along the three-dimensional path. When the velocity of each axis changes drastically, the generation of acceleration causes the machine to be stressed and thus generates errors and vibrations.

\section{Experiment on the Machining Modes with CNC Parameters}

\subsection{CNC Parameters' Tuning Criteria for the Machining Modes}

Different workpieces have different requirements in the machining process, such as aerospace or difficult-to-cut materials, which require higher efficiency for material removal; the surface quality and accuracy are not the priority requirements, as defined in the HS mode. Regarding the structure of the wing used in aerospace, the product demand is high geometric accuracy. As surface quality was not the priority requirement for this product, it was defined via the HP mode. The mold of the optical component needs to have good surface quality and the accuracy needs at least to match the requirement, so it defines with the HQ mode. The tuning criteria of the CNC parameters for the three kinds of the machining mode are summarized in Figure 6. The relationship between the CNC parameters' tuning criteria of the three machining modes is defined below:

- HS mode: The objective is to set the feed motion of machine tools suitable for the larger dynamic errors. It will finish the tool path with the shortest time for motion. In order to reach the target, the CNC parameters' values of jerk, acceleration, corner velocity, and arc velocity must be increased. At the same time, the HS mode will cause larger oscillation after the Acc/Dec motion, and it will mark the vibration texture on the surface.

- HP mode: The dynamic errors should be kept to a minimally tight tolerance. The motion path is close to the ideal path of the NC code. In order to reach the goal, the values of jerk, acceleration, corner velocity, and arc velocity must be reduced for HP mode. Therefore, the smaller values of the $\mathrm{CNC}$ parameters result in larger cycle time.

- HQ mode: The goal is to obtain a smoother machining surface. This means that we must maintain minimal oscillation during feed motion. In addition to reducing the values of jerk, acceleration, corner velocity, and arc velocity, smoothing time constant must be provided to restrain the mechanical resonance. The magnitude of the dynamic errors is between the HS mode and HP mode. In the HQ mode, the motion hardly oscillates, and, therefore, contributes to the smooth surface quality on the geometric surface of the product. 


\section{HS mode}

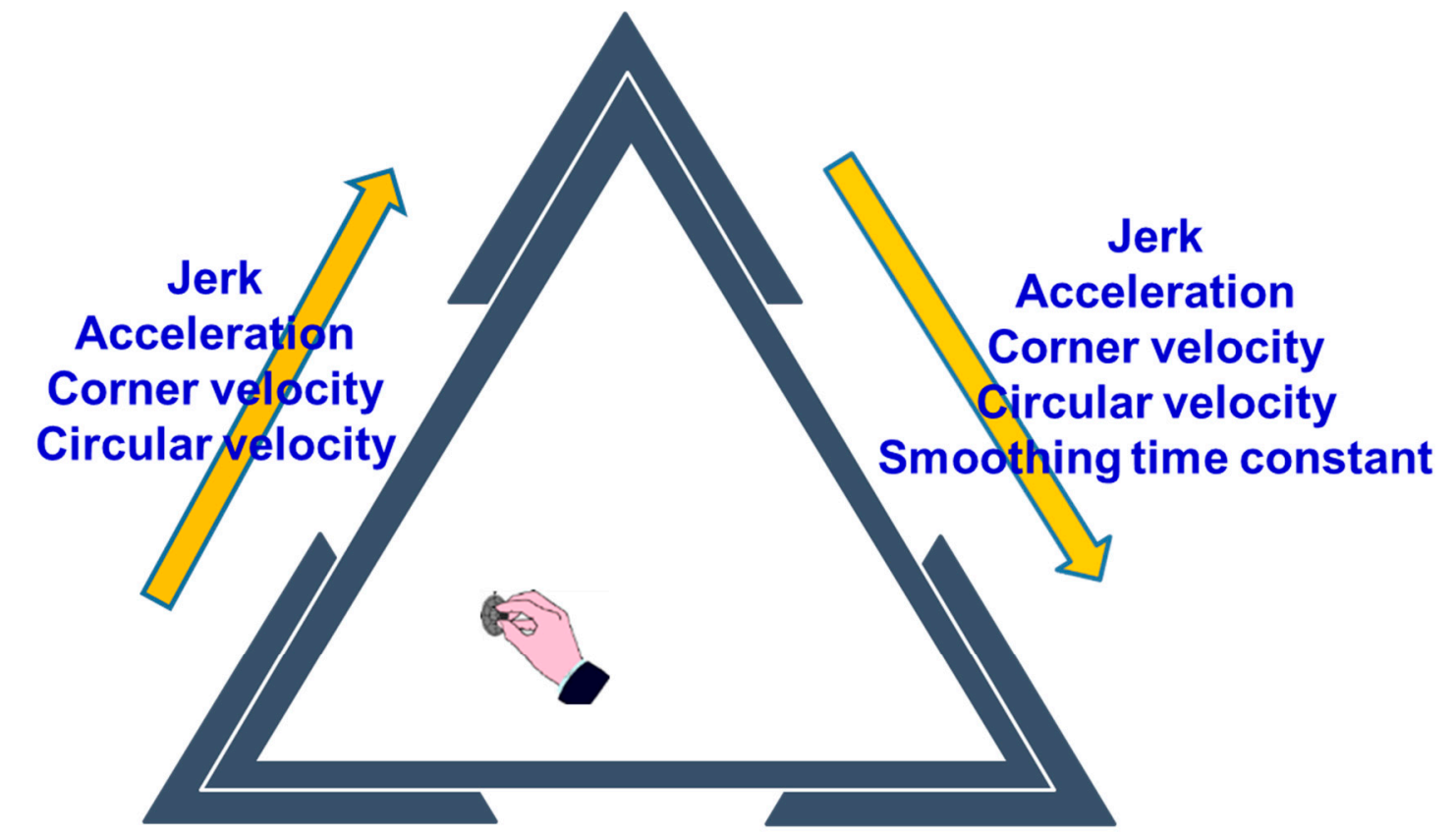

HP mode

HQ mode

\section{Smoothing time constant}

Figure 6. The tuning criteria of the three machining modes.

\subsection{Experimental Platform}

The experiments were performed on a three-axis machine tool with SYTEC's PC-based CNC controller, and DELTA's ASDA-A2 servo motor and servo driver. The absolute encoder was implemented in the servo motor and the linear scale was mounted on the feed drive system. The resolution of linear scale was $1 \mu \mathrm{m}$ for the HEIDENHAIN LS100-series. The software of ASDAsoft was used to ensure the operating system with real-time performance.

The experiments presented how to verify the validity of the tuning criteria of the three machining modes based on several specified paths, such as straight, square, and circular paths. According to the requirements of tool-path planning, the relevant $\mathrm{CNC}$ parameters are listed in Table 1 . In addition to the path geometries and feedrate of NC code, the acceleration profile of the triangle or trapezoid was planned via the $\mathrm{CNC}$ parameters in the table for the tool-path planning, such as preset jerk $\left(J_{p}, \mathrm{~N} 100\right)$, acceleration $\left(A_{p}, \mathrm{~N} 200\right)$, and time constant of Acc/Dec $\left(T_{p}, \mathrm{~N} 300\right)$, and then included the corner velocity $\left(V_{c}, \mathrm{~N} 500\right)$, arc velocity $\left(V_{a}, \mathrm{~N} 600\right)$, and smoothing time constant $\left(T_{a}, \mathrm{~N} 400\right)$. The $J_{p}, A_{p}$, and $T_{p}$ will be limited by the CNC parameters of each axis based on the tool-path planning in the interpolator, such as the $J_{x}$ (N101), $J_{y}(\mathrm{~N} 102), J_{z}$ (N103), $A_{x}$ (N201), $A_{y}(\mathrm{~N} 202), A_{z}$ (N203), $T_{x}(\mathrm{~N} 301), T_{y}$ (N302), and $T_{z}$ (N303). Therefore, when testing for specified paths, the $J_{x}, J_{y}, J_{z}, A_{x}, A_{y}$, and $A_{z}$ have to be set to extreme limits and the $T_{x}, T_{y}$, and $T_{z}$ have to be set to zero. Its advantage is that the $J_{p}$ and $A_{p}$ of the path can be fully presented. It is useful to estimate the relationship between the CNC parameters and dynamic errors. In addition, in order to understand the efforts of CNC parameters, the feedrate has to be kept the constant value for specified paths in the NC code. The geometrical shape of NC code is $S_{g}$ as the idea position, the CNC controller completing the position command $\left(S_{c x}, S_{c y}, S_{c z}\right)$ required for each axis servo loop, and the feed motion resulted in actual position $\left(S_{a x}, S_{a y}, S_{a z}\right)$ source from linear scale. The $S_{c x}, S_{c y}, S_{c z}$ and $S_{a x}, S_{a y}, S_{a z}$ were measured and stored by the ASDAsoft, and the numerical analysis was performed with MATLAB. 
Table 1. CNC parameters corresponding to the tool-path planning.

\begin{tabular}{cccc}
\hline No. & Symbol & Description & Unit \\
\hline N100 & $J_{p}$ & Maximum jerk for tool-path movement & $\mathrm{m} / \mathrm{s}^{3}$ \\
N101 203 & $J_{x}, J_{y}, J_{z}$ & Maximum jerk for each axis movement & $\mathrm{m} / \mathrm{s}^{3}$ \\
N200 & $A_{p}$ & Maximum acceleration for tool-path movement & $\mathrm{m} / \mathrm{s}^{2}$ \\
N201 203 & $A_{x}, A_{y}, A_{z}$ & Maximum acceleration for each axis movement & $\mathrm{m} / \mathrm{s}^{2}$ \\
N300 & $T_{p}$ & Time constant of Acc/Dec for tool-path movement & $\mathrm{ms}$ \\
N301 303 & $T_{x}, T_{y}, T_{z}$ & Time constant of Acc/Dec for each axis movement & $\mathrm{ms}$ \\
N400 & $T_{a}$ & Smoothing time constant for tool-path movement & $\mathrm{ms}$ \\
N500 & $V_{c}$ & Maximum corner velocity for tool-path movement & $\mathrm{mm} / \mathrm{min}$ \\
N600 & $V_{a}$ & Maximum arc velocity for tool-path movement & $\mathrm{mm} / \mathrm{min}$ \\
\hline
\end{tabular}

According to the various paths and the relevant $\mathrm{CNC}$ parameters, we designed the experimental conditions to validate how the CNC parameters influence the dynamic errors when the machine was set as HS, HP, and HQ mode individually. On the other hand, the experimental data was collected as an important basis for the tuning methodology of $\mathrm{CNC}$ parameters.

\subsection{Parameters' Analysis by Straight Path}

Figure 7 shows the experimental results of the straight path with distance $350 \mathrm{~mm}$ and feedrate $60,000 \mathrm{~mm} / \mathrm{min}$. Herein, three selections of CNC parameters were introduced for the HS mode, as shown in Figure 7 (blue solid line: N100 is $200 \mathrm{~m} / \mathrm{s}^{3}, \mathrm{~N} 200$ is $6.8 \mathrm{~m} / \mathrm{s}^{2}$; green dashed line: N100 is $200 \mathrm{~m} / \mathrm{s}^{3}$, N200 is $9.8 \mathrm{~m} / \mathrm{s}^{2}$; red dotted line: $\mathrm{N} 100$ is $100 \mathrm{~m} / \mathrm{s}^{3}, \mathrm{~N} 200$ is $9.8 \mathrm{~m} / \mathrm{s}^{2}$ ) and the command signals for position, velocity, acceleration, and jerk were observed by the CNC controller. With the blue solid line with larger jerk and smaller acceleration limit, it was easy to reach the accelerated limitation. The acceleration profile was trapezoidal and the path completion time was $t_{l 1}$. The green dashed line had the increased acceleration limitation. The acceleration was larger than in the first condition, and the time of Acc/Dec was shorter than in the first condition, so that the path completed time $t_{l 2}$ was shortened. With the red dotted line, although the accelerated limitation was larger and the jerk was smaller, the acceleration profile was triangular. The third condition path completed time was the longest $t_{l 3}$. Finally, the path completion time was compared to $t_{l 3}>t_{l 1}>t_{l 2}$, and the $t_{12}$ was the shortest time to complete the machining process. This result verified that the HS mode had larger $J_{p}$ and $A_{p}$.

The first condition had a short acceleration time, but it was limited by the acceleration setting parameter N200. Therefore, the profile was a trapezoidal acceleration profile. This was a disadvantage for the machine because the machine received force for a long period, which made machine dynamic errors or oscillations happen more easily. The second condition set an upper acceleration limitation, thus shortening the segment time during acceleration and deceleration. If the dynamic characteristics' performance of the servo and the machine are raised, the maximum accelerated limitation can be increased, so that it can be a triangular acceleration profile, and the path completion time can be reduced. The acceleration profile was triangular for the third condition. The jerk could reach the maximum acceleration directly, but the maximum acceleration was not large enough, making the finishing time longer; the path completion time was finally increased. However, the larger $J_{p}$ and $A_{p}$ will excite the resonance of the machine, which will cause vibration during the feeding process, and the workpiece surface will suffer worse oscillation textures. Since HQ mode pursues good surface quality, it needs to maintain a constant feedrate by avoiding acceleration and deceleration during the motion, since the feed force instantaneously causes vibration on the machine (as shown in Figure 8) during acceleration and deceleration. Then, some distinct vibration caused the surface of the workpiece to become rough. However, it is impossible that no acceleration or deceleration occurred during the motion of the three-dimensional path. Therefore, the HQ mode is not meant to preclude small dynamic errors. Its significance is in reducing the oscillation caused by acceleration and deceleration of each axis. The oscillation of the Acc/Dec machine cannot be defined by the $\varepsilon_{1}$ after interpolation; the oscillated behavior resulted from the dynamic characteristics of the real machine. Therefore, the HQ mode 
was used to observe the tracking error of each axis, reduce the oscillation of the feed drive system during the period of acceleration and deceleration, and avoid the rough surface on the workpiece. The Acc/Dec is equivalent to an impact on the input of the mechanism. If the bandwidth of the impact is greater than the resonance mode of the machine, the resonance is easily excited. Generally, the controller smoothed the oscillation during acceleration and deceleration by the filter for the time constant parameter. The function of the filter was to ensure smooth path velocity but it increased the completion time of the machining and the dynamic errors of the path. Figure 9 shows the experimental results of a straight path whose distance was $25 \mathrm{~mm}$, acceleration was $10 \mathrm{~m} / \mathrm{s}^{2}$, and feedrate was $6000 \mathrm{~mm} / \mathrm{min}$ with different filter $T_{a}(\mathrm{~N} 400)$. Figure 9 shows the tracking error for a single axis, and it also shows the spectrum of the fast Fourier transformation (FFT) based on the tracking error. The spectrum can be observed that there were two peaks caused by the oscillation of the feed drive system. Their resonance frequencies were 38 and $46 \mathrm{~Hz}$, respectively. The first resonance should have been suppressed by the proper $T_{a}$. It can be observed that after the $T_{a}$ was $26 \mathrm{~ms}$, the first resonance was suppressed. If the $T_{a}$ was based on the second resonance frequency, then the oscillation still was excited for the feed drive system. For the tracking error, it was found that after increasing $T_{a}$, the oscillation was reduced after passing of the Acc/Dec (red line in Figure 9). In addition, when the $T_{a}$ was 0 , the path completion time was $t_{s 1}$. When the $T_{a}$ was $26 \mathrm{~ms}$, the path completion time was extended to $t_{\mathrm{s} 2}$. In this case, the $T_{a}$ was $0 \mathrm{~ms}$ for the HS mode, and the $T_{a}$ was $26 \mathrm{~ms}$ for the HQ mode.

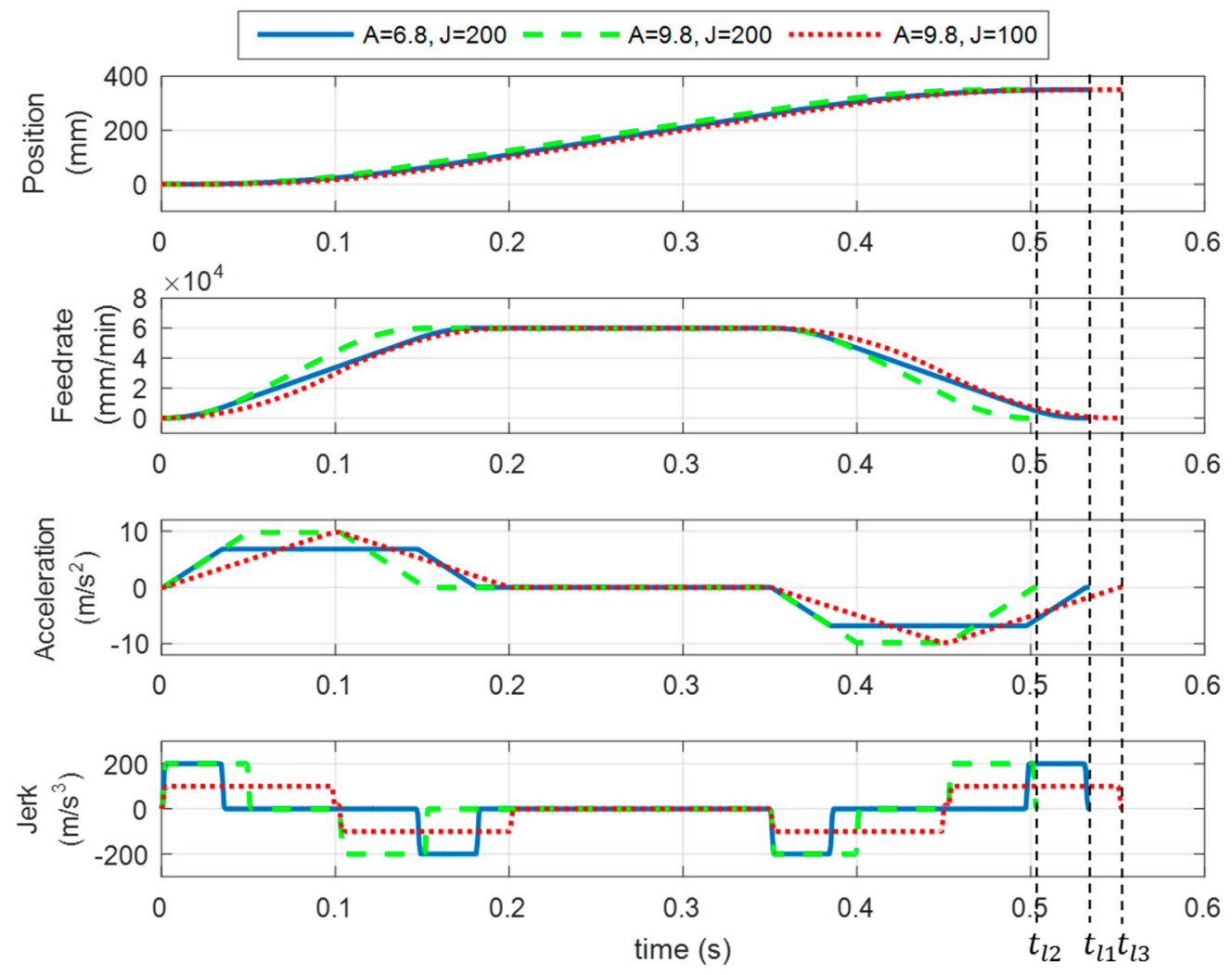

Figure 7. Analysis of straight path with different parameters. 

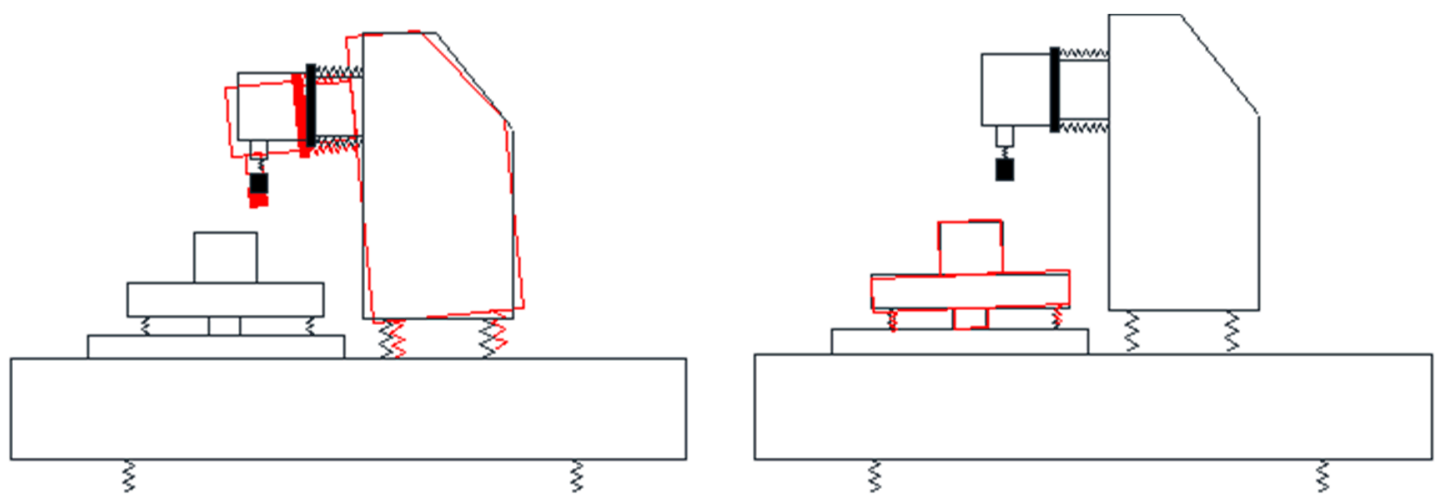

Figure 8. The oscillation caused by feed motion in the feed drive system.

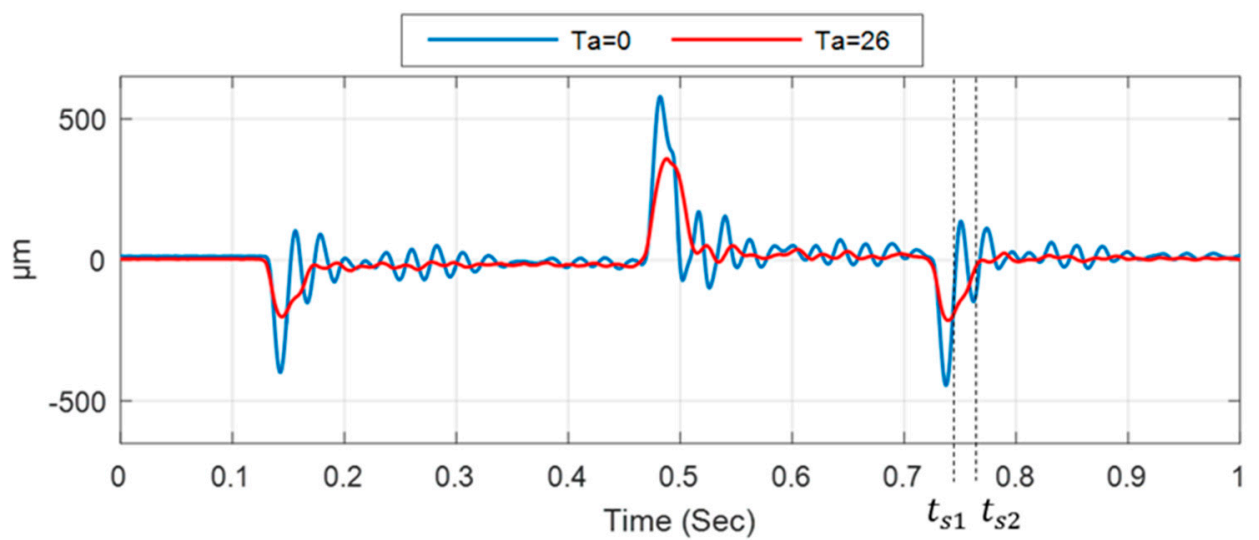

FFT

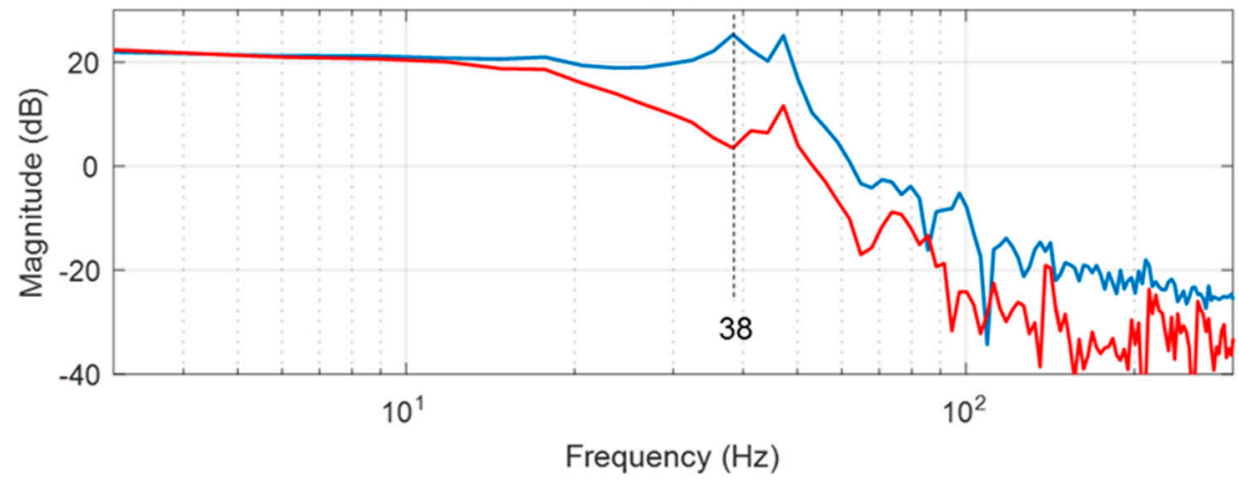

Figure 9. The smoothing time constant $\left(T_{a}\right)$ effect on the tracking error and spectrum.

\subsection{Parameters' Analysis by Square Path}

Figure 10 shows a square path in the left with a side length of $30 \mathrm{~mm}$, feedrate was $5000 \mathrm{~mm} / \mathrm{min}$, acceleration was $4 \mathrm{~m} / \mathrm{s}^{2}$, and jerk was $200 \mathrm{~m} / \mathrm{s}^{3}$ by setting the three different corner velocities (N500), which were $100 / 1000 / 3000 \mathrm{~mm} / \mathrm{min}$, respectively, and observing the influence of the $V_{c}$ at the corners for $C_{1}, C_{2}$, and $C_{3}$. The right of Figure 10 shows the testing result of the $C_{1}$. The larger $V_{c}$ caused larger dynamic errors (green line in Figure 10), and the period time of the path $S_{c}$ was shorter. The smaller $V_{c}$ caused smaller dynamic errors (blue line in Figure 10), and the period time of the path $S_{c}$ was longer.

Figure 11 shows a velocity profile of a typical square path. The diagrams from top to bottom were the $V_{x}, V_{y}$, and $V_{p}$, respectively. The completed time was $t_{c 1}>t_{c 2}>t_{c 3}$ in these results. Figure 12 shows the acceleration profile of the square path. The diagrams from top to bottom were $A_{x}$ and $A_{y}$, respectively. First, observing the velocity and acceleration of $C_{1}, C_{2}$, and $C_{3}$, the larger value of the $V_{c}$ would cause the velocity at the corners to suddenly become discontinuous, resulting not only in a large acceleration but also the $A_{x}$ and $A_{y}$ becoming unstable (green line in Figure 12) at the corners; 
oscillation would occur in the constant velocity section. The smaller $V_{c}$ would cause smooth velocity because the $A_{x}$ and $A_{y}$ reached the set value of the parameter at the corner. The performance of the HP mode included the dimensional accuracy and geometric accuracy of the workpiece, which means the dynamic errors needed to be smallest when the path was performed. In this case, the $V_{c}$ was $3000 \mathrm{~mm} / \mathrm{min}$ for the HS mode, and the $V_{c}$ was $100 \mathrm{~mm} / \mathrm{min}$ for the HP mode. However, if the $V_{c}$ is largest, the completion time is shortest for the path, but the dynamic errors will increase on the corner at the same time.
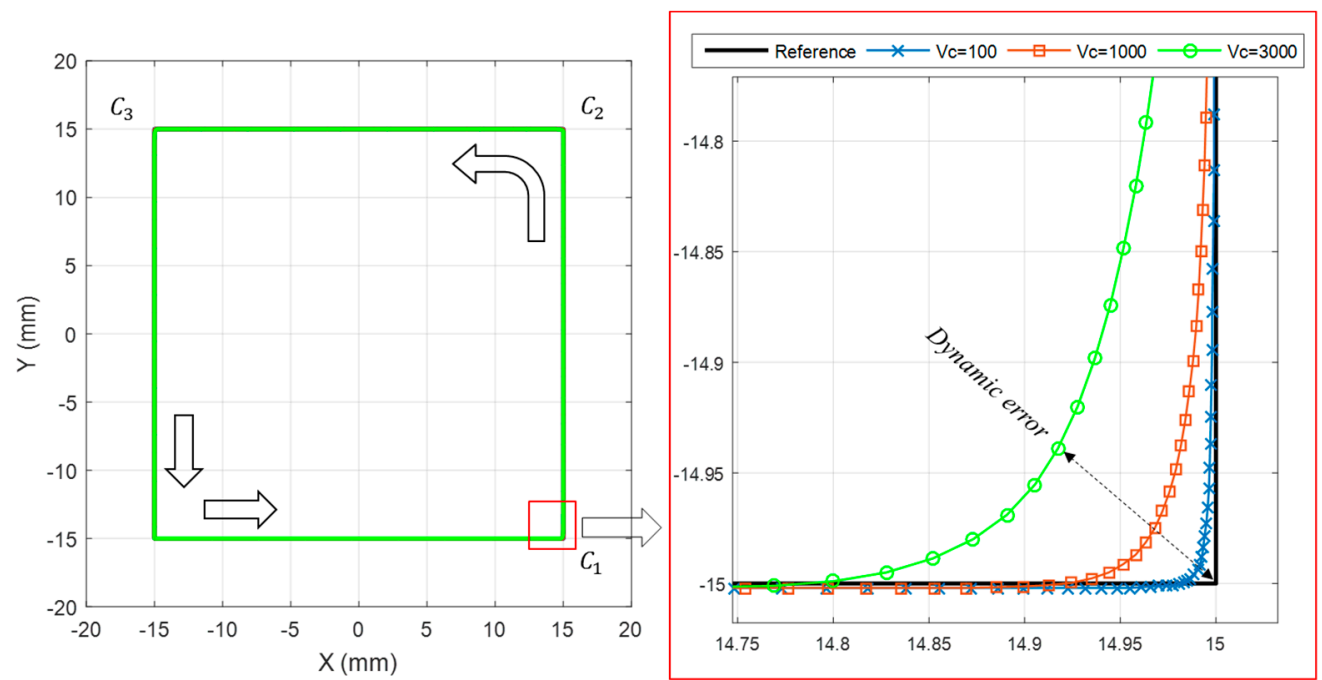

Figure 10. The dynamic errors of the square path.
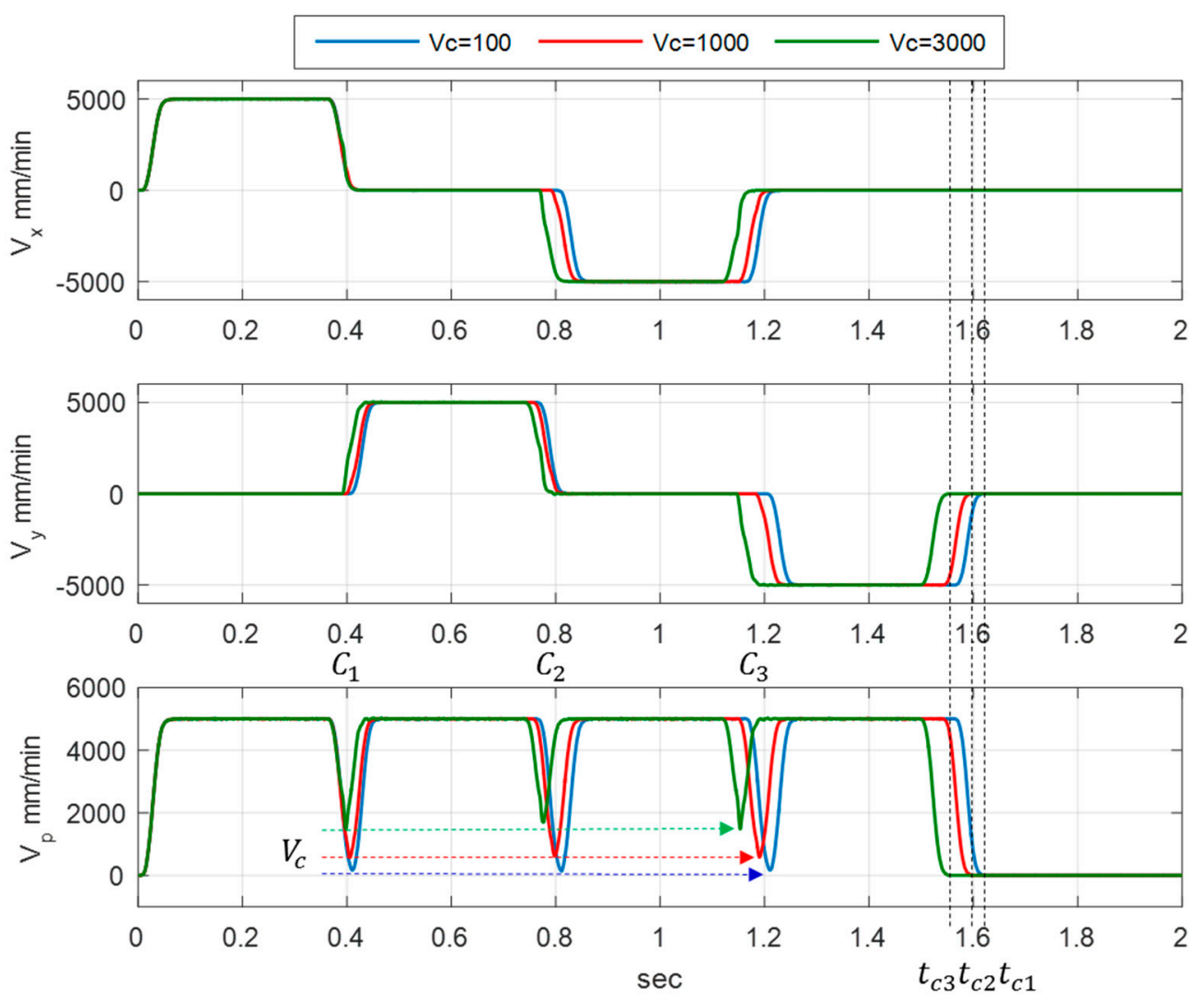

Figure 11. Analysis of square path with different corner velocity $\left(V_{c}\right)$. 


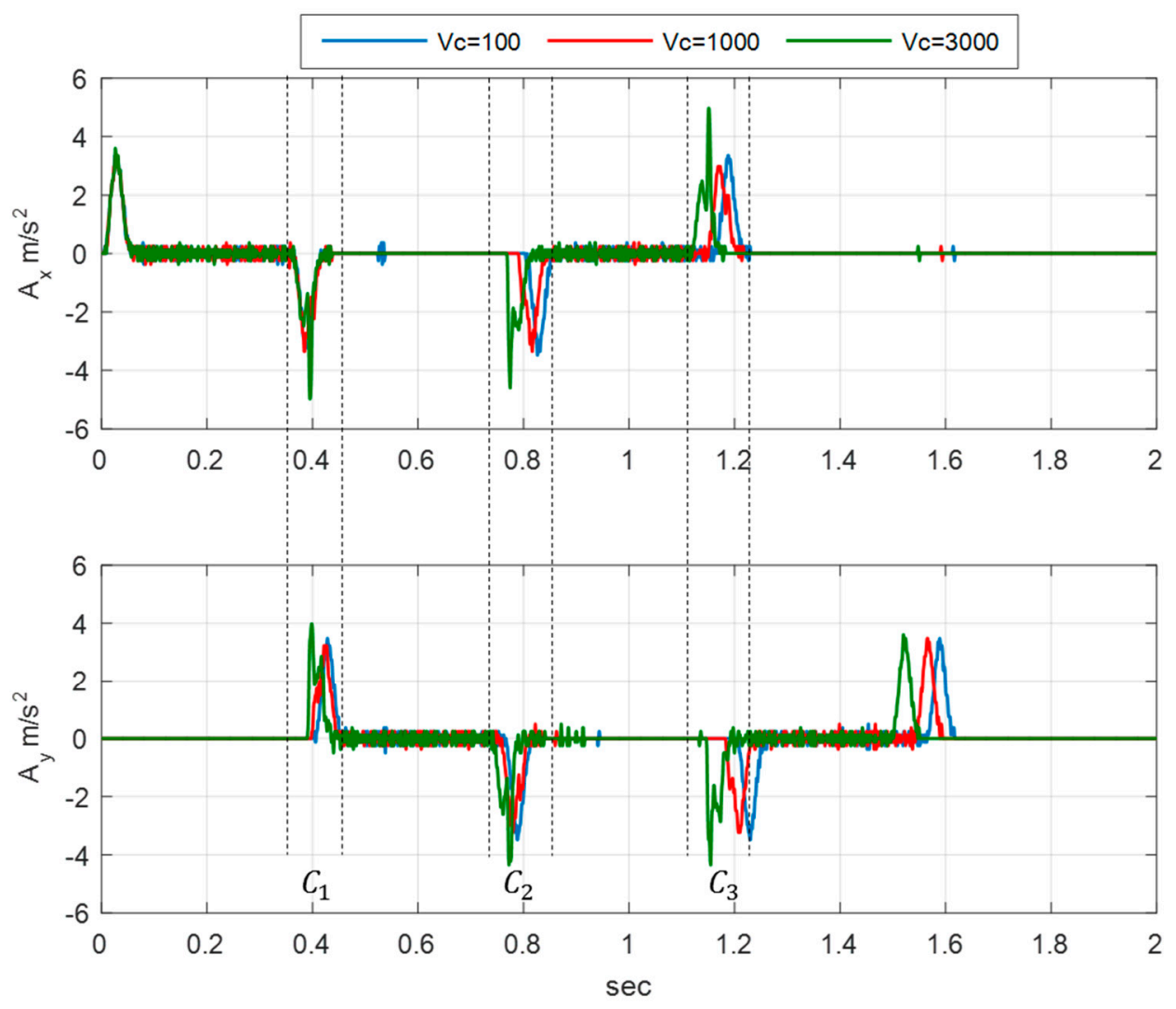

Figure 12. Analysis of the acceleration at each corner with different corner velocity $\left(V_{c}\right)$.

\subsection{Parameters' Analysis by Circular Path}

Figure 13 shows the experimental results of a circular path with a radius of $15 \mathrm{~mm}$, acceleration of $4 \mathrm{~m} / \mathrm{s}^{2}$, and jerk of $200 \mathrm{~m} / \mathrm{s}^{3}$. Adjust the three conditions of different $V_{a}$ (N600) (blue line: $3000 \mathrm{~mm} / \mathrm{min}$; red line: $6000 \mathrm{~mm} / \mathrm{min}$; green line: $9000 \mathrm{~mm} / \mathrm{min}$ ) and observe the feedback signals. In order to easily observe the testing results with variant $V_{a}$, the feedrate of NC code must be greater than $9000 \mathrm{~mm} / \mathrm{min}$; otherwise, $V_{a}$ is limited by the feedrate. Figure 14 shows the conversion of a circular path into a straight line. The diagrams from top to bottom show that actual radius value and dynamic errors were due to different $V_{a}$, respectively. The horizontal axis in the error graph is the angle, and the black line is the reference path. The four quadrants of the circular path, $A_{1}, A_{2}$, $A_{3}$, and $A_{4}$, were the reverse directions of the axis, at the position of the axis where acceleration and deceleration occur. The acceleration value was limited by parameters including N101 103, N201 203, and N301 303. The sharp corners caused the backlash of the feed drive system, and the sharp corners' error value reduced the dynamic errors, so that the influence of $A_{1}, A_{2}, A_{3}$, and $A_{4}$ should not be estimated in the dynamic errors. To analyze the influence of $V_{a}$ on the circular path, a large $V_{a}$ will produce large dynamic errors, and a smaller $V_{a}$ will produce smaller dynamic errors.

Figure 15 shows the velocity curve for a typical circular path. The diagrams from top to bottom present $V_{x}, V_{y}$, and $V_{p}$. The $V_{x}$ and $V_{y}$ are sine waves, and $V_{p}$ had a constant velocity except at the start position and the end position. Comparing the completion time of the path, the result was $t_{a 1}>t_{a 2}$ $>t_{a 3}$. In this case, the $V_{a}$ was $9000 \mathrm{~mm} / \mathrm{min}$ for the HS mode, and the $V_{a}$ was $3000 \mathrm{~mm} / \mathrm{min}$ for the HP mode. However, if the $V_{a}$ is largest, the completion time is shortest for the path, and the dynamic errors increase at the same time. 


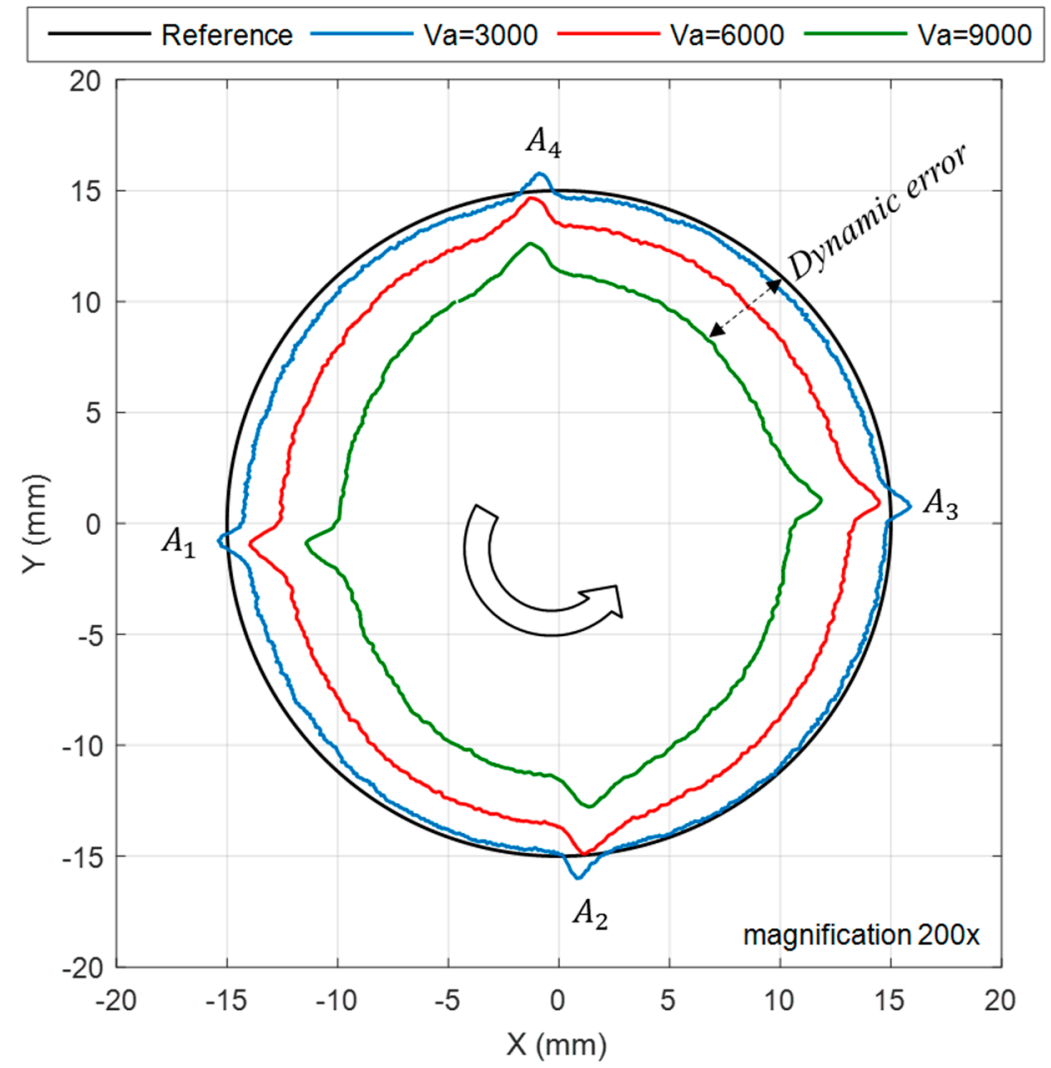

Figure 13. The dynamic errors of the circular path.

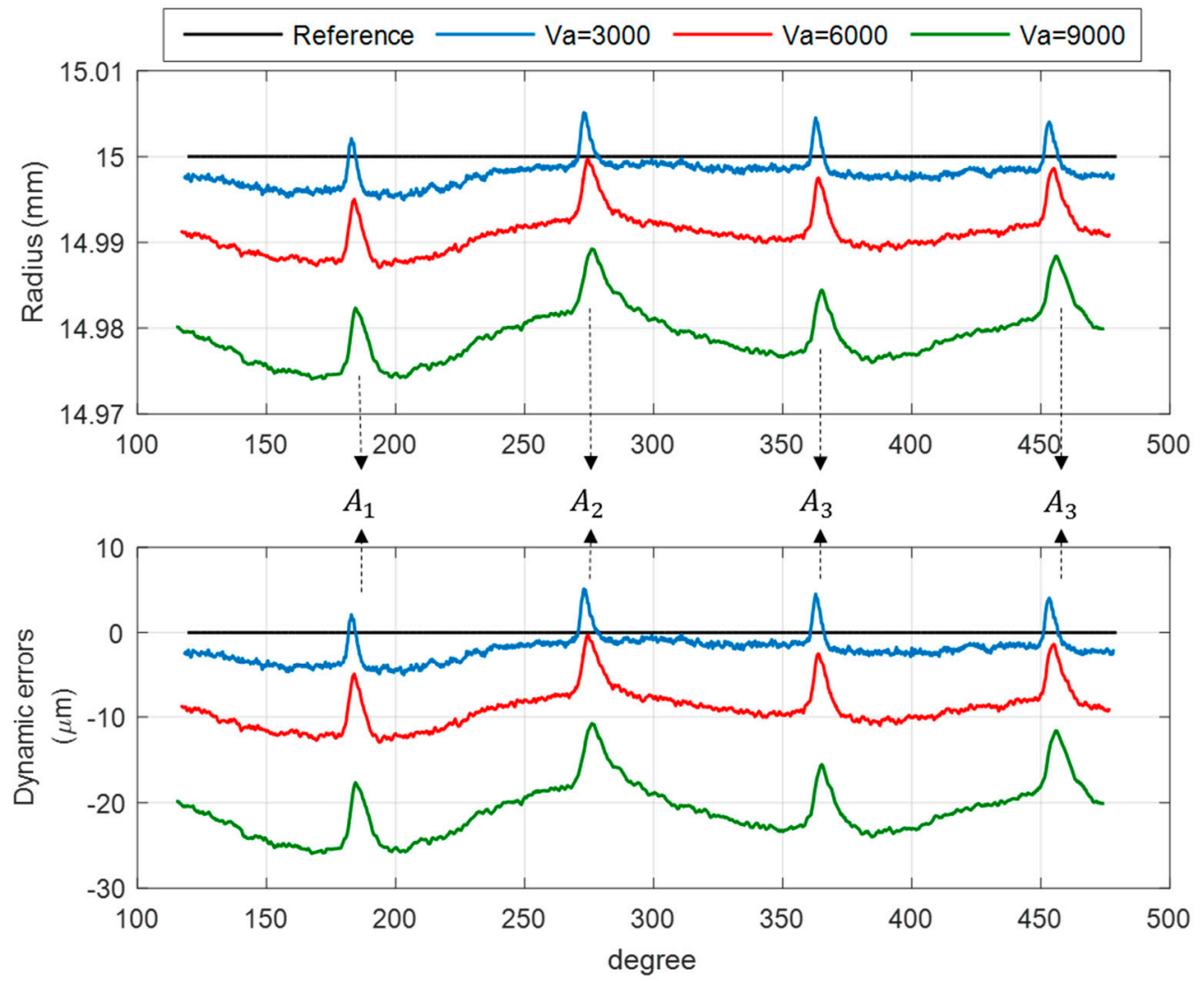

Figure 14. Analysis of circular path for the dynamic errors at all degrees of the whole path. 


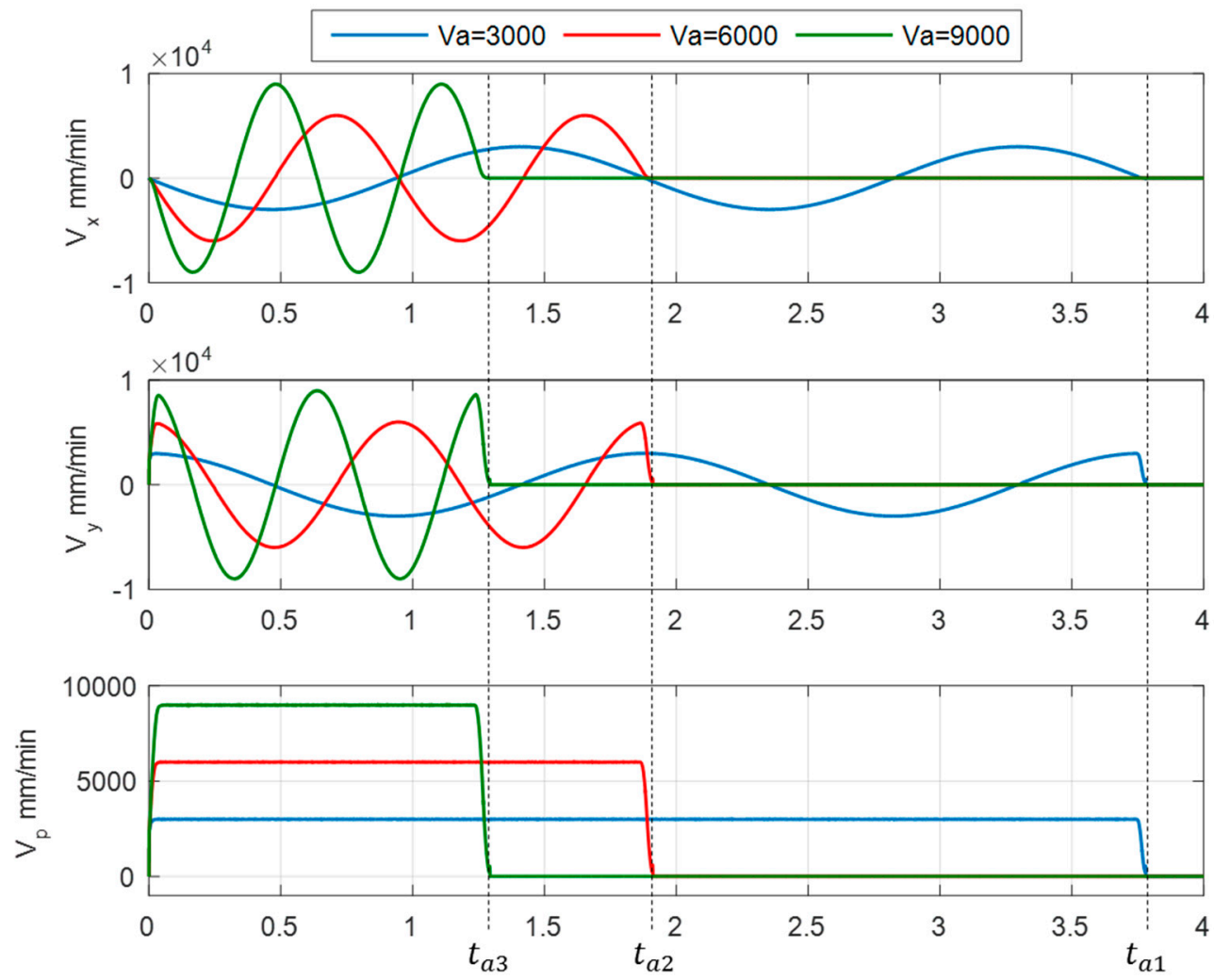

Figure 15. Analysis of circular path for the velocity of the whole path.

In summary, in order to reduce the dynamic errors, the jerk, acceleration, $V_{c}$, and $V_{a}$ need to be reduced properly, so that the advantage of HP mode is fewer dynamic errors, but the path completion time becomes longer. In general, HP mode is used for the finishing process, and most machining requirements are dimensional accuracy and geometric accuracy. However, mold processing needs more dimensional accuracy requirement, not geometric accuracy.

\section{Tuning Methodology and Procedure for the CNC Parameters}

The relationship between CNC parameters and the three machining modes was verified in Section 3. The experimental results showed the effectiveness of our proposed machining mode for corresponding CNC parameters, which is relevant to the dynamic errors of the machine. The tuning methodology and procedures of the CNC parameters were defined by the simple path, as shown in Figure 16. Firstly, the anticipated dynamic errors were defined as the maximum magnitude of the tool path that had first been allowed. In this paper, the anticipated dynamic errors of the HS/HP/HQ mode were set to $0.05 / 0.01 / 0.02 \mathrm{~mm}$, respectively. Actually, the anticipated dynamic errors had no absolute value. They must to be adjusted by the operator for the product requirements. The specified paths used the relevant feedrate for testing. We suggest the proper feedrate that the machining condition used. According to anticipated dynamic errors and the circular test, the $A_{p}$ and $V_{a}$ could be easily calculated based on Equation (1), secondly. For the $A_{p}$ and straight test, the $J_{p}$ was calculated. The $T_{a}$ and $V_{c}$ were estimated based on the square test. The tuning procedure was based on actual measurement of the machine's two-dimensional contouring performance. The machine's dynamic errors were measured with simple paths, and the best combination of CNC parameters were chosen. A practical methodology will be discussed in this section in detail. 


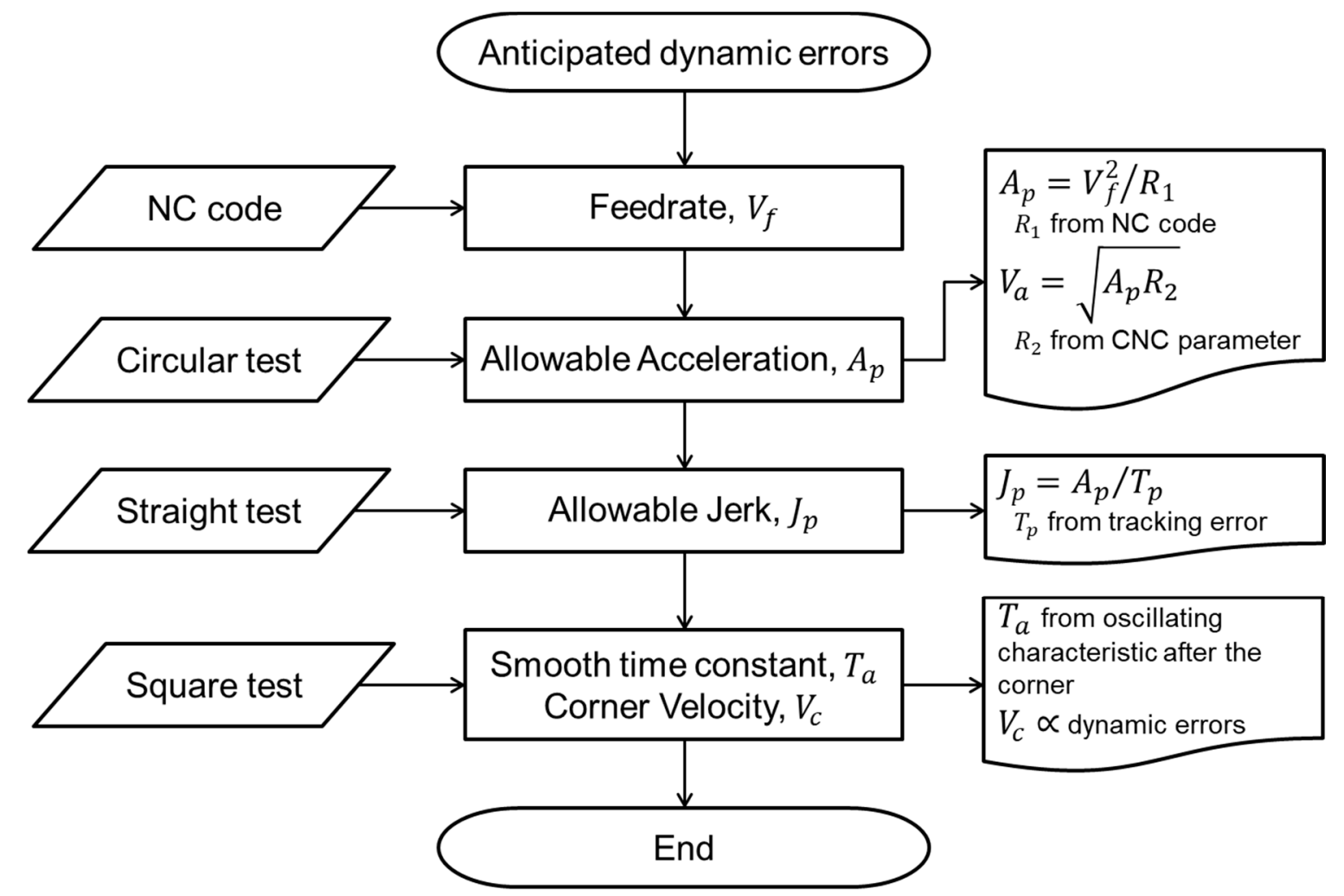

Figure 16. CNC parameter tuning methodology and procedure.

\subsection{Allowable Acceleration}

The acceleration of any axis results from the force caused by the feed drive system, and leads to contour error on the components. This means that by measuring dynamic errors and correlating them to effective acceleration, maximum allowable acceleration values for each axis can be set depending on the anticipated path accuracy. According to the circular testing, the dynamic errors can be evaluated due to the limited circle radius $R$. With small circles and increasing $V_{a}$, the required acceleration values $A_{a}$ become very high (Equation (1)). Examples can be seen in Figures 13 and 14. According to Newton's second law and Hooke's law expressed as:

$$
F=m a=k \Delta x
$$

where $m$ and $k$ are equivalent mass and equivalent stiffness, which are assumed the constants for the closed loop feed drive system in this paper, they are usually hard to tune by the machine operator. The $a$ and $\Delta x$ are acceleration and deformation of system. According to Equation (5), we can easily understand the relationship between acceleration and dynamic errors. Finally, the equation of acceleration and dynamic errors was obtained by the linear regression method expressed as:

$$
A_{p}=A_{a}=63.551 \times \varepsilon_{3}-0.1543
$$

where $A_{p}$ is allowable acceleration for path movement, $A_{a}$ is allowable acceleration for axis movement, and $\varepsilon_{3}$ is anticipated dynamic errors. According to Equation (6), the allowable acceleration has limits of $\mathrm{HS} / \mathrm{HP} / \mathrm{HQ}$ modes: $3.02 / 0.48 / 1.12 \mathrm{~m} / \mathrm{s}^{2}$, respectively. Therefore, these tests are useful for verifying the allowable acceleration value. This means that the CNC parameters related to acceleration can be evaluated. When the NC code was a circular path, the N600 of CNC parameters will be defined by the radius of curvature and Equation (1). In this paper, the radius of curvature of the commercial controller was $5 \mathrm{~mm}$, and the arc velocities in HS/HP/HQ mode were 7373/2939/4490 mm/min, respectively. 


\subsection{Allowable Jerk}

The jerk profiles were similar to the impact force on the mechanical structure. The jerk is a dynamic excitation of the machine, which will cause oscillation in its structure resonance, meaning relative displacements between tool and workpiece, as illustrated in Figure 8. The oscillating characteristic is created by the driving torque or force. This means the measured tracking error of the relevant resonance frequencies can be identified with FFT. For this reason, the allowable jerk values for each axis can be identified at the same time. According to the straight path testing, the mechanical resonance can be identified with tracking error, as illustrated in Figure 9 (blue line). The first resonance of machine was about $38 \mathrm{~Hz}$. The allowable jerk $\left(J_{p}\right)$ can be evaluated due to the time constant of Acc/Dec $\left(T_{p}\right)$ and allowable acceleration $\left(A_{p}\right)$ (maximum value $J_{p}=A_{p} / T_{p}$ ). The allowable acceleration was set in Section 4.1 , and the allowable jerk limits of $\mathrm{HS} / \mathrm{HP} / \mathrm{HQ}$ mode were $114.88 / 18.29 / 42.44 \mathrm{~m} / \mathrm{s}^{3}$, respectively. It means that the $\mathrm{CNC}$ parameters related to jerk can be evaluated.

\subsection{Smoothing Time Constant}

The smoothing time constant is similar to the filter, which can smooth the velocity profiles in tool-path planning. The smoothing filter must be designed such that it cancels the mechanical resonance. Its time constant must be set at the inverse of the resonance frequency. According to the square path testing, dynamic errors can be observed at the corner, as illustrated in Figure 17. The oscillation can be seen on the straight line after the corner. In Figure 18, the time constant of the solid line was $0 \mathrm{~ms}$, and the time constant of the dotted line was $26 \mathrm{~ms}$. The result shows that the longer time constant helped to reduce the oscillation of the workpiece surface during machining, but increased contour error and cycle time in machining parts.

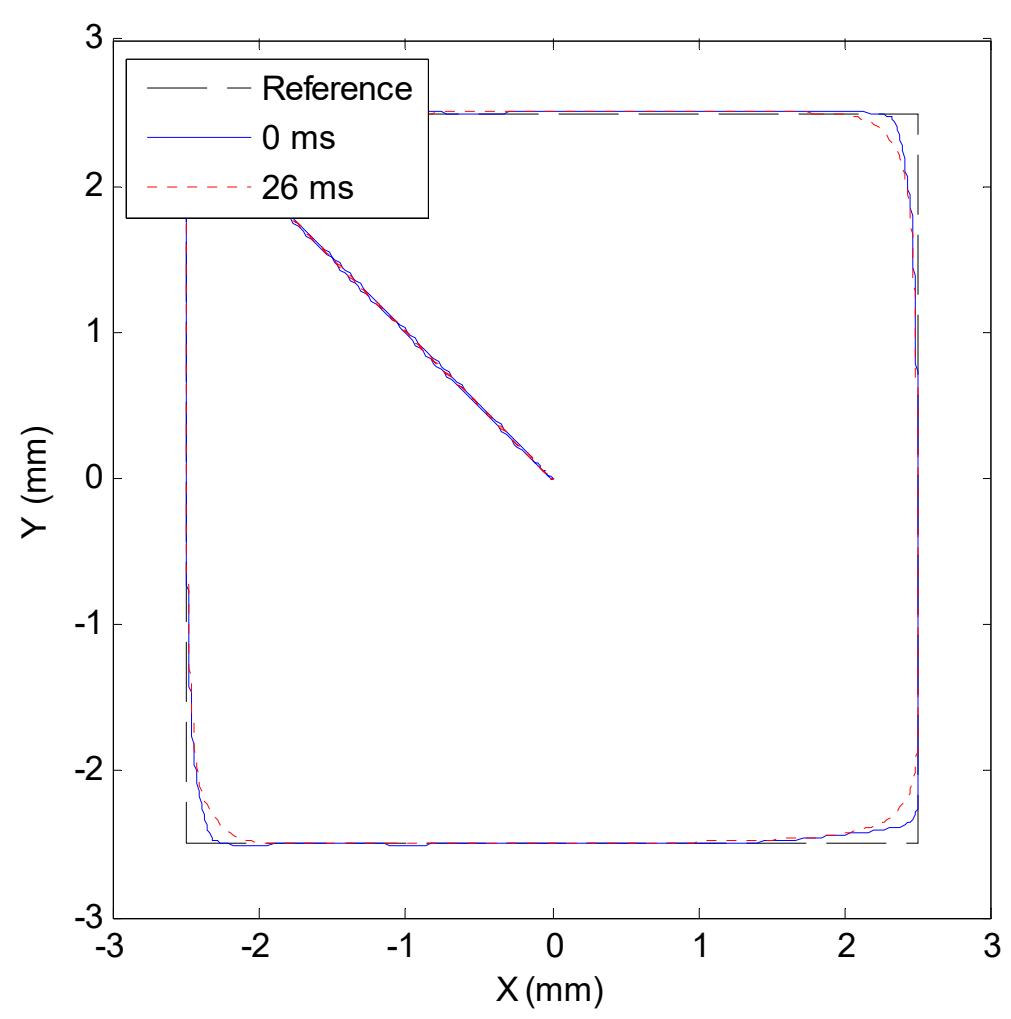

Figure 17. The smoothing time constant led to the contour error. 

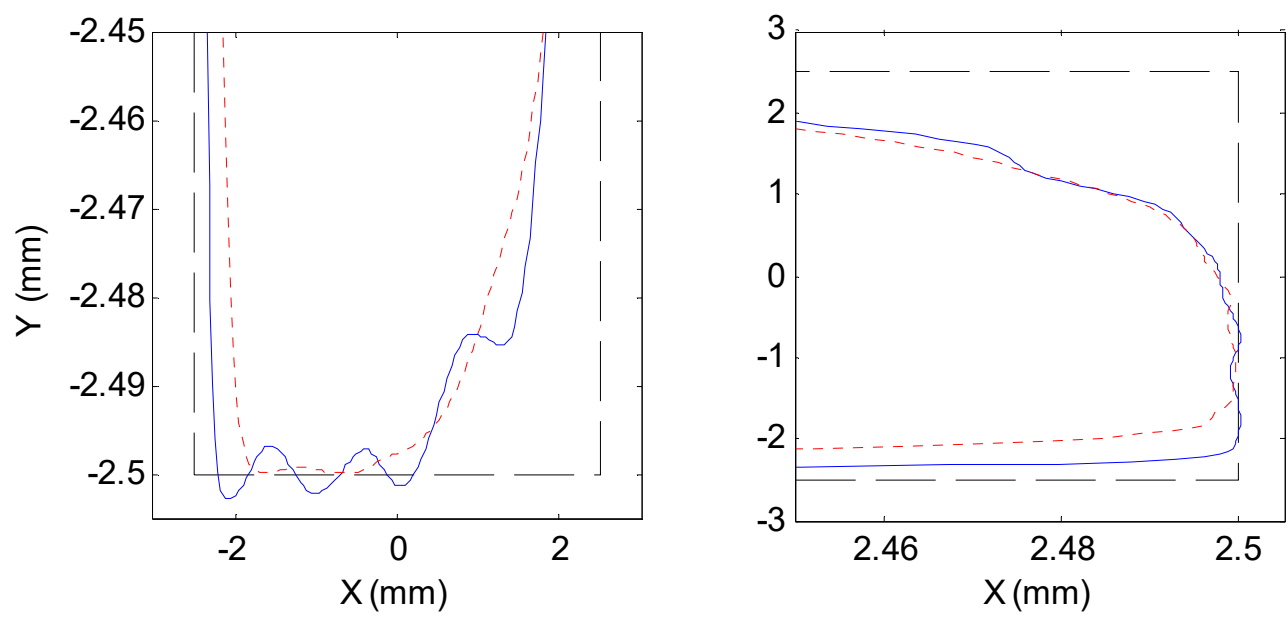

Figure 18. The smoothing time constant led to the oscillation of the tool path.

\subsection{Corner Velocity}

A higher corner velocity is useful for shorter cycle time, but it would cause larger dynamic errors (or corner error). If it is too high, it easily causes structural vibration at the corners. The vibration could be decreased by the smoothing time constant, but the errors would be increased at the corners. The corner velocity is proportional to the corner error. However, the corner error also includes the effect of the tracking error from the servo loop. However, while there is a lot of domain knowledge to tune the tracking error, it is not easy for the machine operator to use. Therefore, this paper regarded the servo loop as a black box. We proposed the experimental methods to create the relationship between the corner velocity and corner error. According to the experimental results of Section 3.4 for square path testing, the dynamic errors can be observed at the corner. We fed the different jerk, acceleration, $V_{c}$, and feedrate for the square path, respectively, summarized as follows:

- The larger jerk and acceleration will increase the corner error as the feedrate increases.

- There are two sets of parameters: One is $J_{p}=100 \mathrm{~m} / \mathrm{s}^{3}$ and $A_{p}=2.5 \mathrm{~m} / \mathrm{s}^{2}$, and the other one is $J_{p}=50 \mathrm{~m} / \mathrm{s}^{3}, A_{p}=1.2 \mathrm{~m} / \mathrm{s}^{2}$. The corner errors are more stable than the other set of parameters for the different feedrates.

- If the $V_{c}$ is set to $3000 \mathrm{~mm} / \mathrm{min}$, when the feedrate exceeds $3000 \mathrm{~mm} / \mathrm{min}$, the corner errors are more stable. This is caused by the current feedrate being lower than the anticipated $V_{c}$. The $V_{c}$ will give priority to the current feedrate for tool-path planning.

The experimental data on the square path were used to estimate the maximum corner errors of each measurement result. The jerk, acceleration, $V_{c}$, and feedrate by the test conditions were considered as inputs, and the corner errors as outputs. Multiple regression analysis was used to obtain the regression formula for the inputs and outputs. Finally, the maximum corner error was set to the dynamic errors of the HS/HP/HQ modes expected in this paper. The feedrate was $4000 \mathrm{~mm} / \mathrm{min}$ for the square path, the allowable acceleration, and allowable jerk, in Sections 4.1 and 4.2 , as the inputs of the regression formula, and solving the allowable $V_{c}$ of the $\mathrm{HS} / \mathrm{HP} / \mathrm{HQ}$ modes. The corresponding $V_{c}$ were $1470 / 250 / 550 \mathrm{~mm} / \mathrm{min}$, respectively.

\section{Experimental Validation}

In Section 3, the experimental results showed the effectiveness of our proposed machining modes for corresponding CNC parameters, which is relevant to the dynamic errors of the machine. According to the tuning methodology and procedures of the CNC parameters implemented, the relevant CNC parameters were estimated based on the anticipated dynamic errors in Section 4. This section proposed a single square path with the same $4000 \mathrm{~mm} / \mathrm{min}$ feedrate and the length was $30 \mathrm{~mm}$ to verify the validation of the tuning methodology. We used the three sets of CNC parameters (see Table 2) 
corresponding to the "HS, HP, and HQ modes" in the actual machine platform for validation, thereby observing the performance of the motion dynamic under various modes.

Table 2. CNC parameters for tool-path movement with machining modes.

\begin{tabular}{ccccccc}
\hline No. & Sym. & Description & Unit & HS & HP & HQ \\
\hline N100 & $J_{p}$ & Maximum jerk for tool-path movement & $\mathrm{m} / \mathrm{s}^{3}$ & 114.88 & 18.29 & 42.44 \\
N200 & $A_{p}$ & Maximum acceleration for tool-path movement & $\mathrm{m} / \mathrm{s}^{2}$ & 3.02 & 0.48 & 1.12 \\
N300 & $T_{p}$ & Time constant of Acc/Dec for tool-path movement & $\mathrm{ms}$ & 26 & 26 & 26 \\
N400 & $T_{a}$ & Smoothing time constant for tool-path movement & $\mathrm{ms}$ & 1 & 1 & 26 \\
N500 & $V_{c}$ & Maximum corner velocity for tool-path movement & $\mathrm{mm} / \mathrm{min}$ & 1470 & 250 & 550 \\
N600 & $V_{a}$ & Maximum arc velocity for tool-path movement & $\mathrm{mm} / \mathrm{min}$ & 7373 & 2939 & 4490 \\
\hline
\end{tabular}

The experimental results are listed in Table 3. We observed the time of the completion of the tool path was the fastest for HS mode. In HP mode, the minimum dynamic errors were of the corners. There was small oscillation that was caused by the tracking error after the cornering in HQ mode. According to the experimental results, the servo parameters could be ignored, and the relevant $\mathrm{CNC}$ parameters of the tool-path planning could be adjusted, which can affect the completion time, dynamic errors, and tracking error of the same path.

Table 3. Experimental results for three machining modes.

\begin{tabular}{ccccc}
\hline Description & Unit & HS & HP & HQ \\
\hline Cycle time & $\mathrm{sec}$ & 1.935 & 2.655 & 2.064 \\
Dynamic errors & $\mathrm{mm}$ & 0.053 & 0.018 & 0.026 \\
Tracking error & $\mathrm{mm}$ & 0.007 & 0.003 & 0.001 \\
\hline
\end{tabular}

The comparison of HS, HP, and HQ modes are listed in Table 4. In the HS mode, the completion time of the path was fastest than the other modes. However, the dynamic errors and the tracking error were increased by $66 \%$ and $85 \%$, respectively. In the HP mode, although the completion time of the path was increased by $37 \%$ compared with the HS mode and the tracking error was increased by $28 \%$, the HP mode was closed to the ideal path with highest accuracy. In the HQ mode, the surface quality of the workpiece was improved by focusing on reducing the machine resonance, although the dynamic errors were worse than the HP mode. The surface quality improved by $85 \%$ compared with the HS mode. However the completion time was only increased by $6 \%$ compared with the HS mode.

Table 4. Comparison of three machining modes from the experimental results.

\begin{tabular}{cccc}
\hline Description & HS & HP & HQ \\
\hline Cycle time & $0 \%$ & $37 \%$ & $6 \%$ \\
Dynamic errors & $66 \%$ & $0 \%$ & $16 \%$ \\
Tracking error & $85 \%$ & $28 \%$ & $0 \%$ \\
\hline
\end{tabular}

The experimental results verified the tuning methodology for CNC parameters of Section 4. We found that no single set of CNC parameters was able to simultaneously satisfy all of the three machining modes: "High speed", "high accuracy", and "high surface quality". Actually, these three machining modes often contradict each other. For example, we may have the "high productivity", but with "low accuracy and poor surface finish."

\section{Conclusions}

Since the required product quality affected CNC parameters of the machine tools, the CNC parameters must be selected to vary the machining performance of the tool-path planning, named as 
HS, HP, and HQ modes, respectively. Actually, the manufacturer provided only a single set of CNC parameters for the commercial CNC machine tools. It was not enough for the different machining requirements. However, the performance of the servo loop and actual machine was fixed and was hard to be tuned, another reason for needing to have quite a domain knowledge to tune the CNC parameters' requirements. Therefore, the operator of the machine cannot easily process the different machining requirements. This paper introduced the relationship of CNC parameters, dynamic errors, and machining modes. The dynamic errors defined the difference of the ideal position for NC code to the actual position for linear scale in this study. According to the anticipated dynamic errors for the three machining modes and feed motion testing by several specified paths' experiment, such as straight, square, and circular paths in actual machine tools, the HS, HP, and HQ modes can be achieved by properly tuning the CNC parameters via the tuning methodology. The experimental results proposed an approach that contained three sets of CNC parameters. The CNC parameters were selected to be larger values of $J_{p}, A_{p}, V_{c}$, and $V_{a}$, the path completion time was shortened, and the processing efficiency improved to match the HS mode. However, the corresponding dynamic errors became larger, which sacrificed accuracy and surface quality. On the other hand, the smaller values of CNC parameters resulted in larger completion time and smaller tracking error, and the geometric accuracy was improved to reach the HP mode. The HQ mode dealt with the worse surface quality of the product, caused by feed force for the feed motion. When the feed motion experienced oscillation on the corner or circular paths, the exact $T_{a}$ reduced the impact of feed force during the high Acc/Dec period. Although the dynamic errors of $\mathrm{HQ}$ mode were larger than in the HP mode, the oscillation could be reduced during the feed motion. If there is larger oscillation occurring in the HS mode, in addition to the reduction in $J_{p}, A_{p}, V_{c}$, and $V_{a}$, it can also use the $T_{a}$ to decrease the oscillation for the smooth surface quality of the geometric shape. However, the cycle time became longer, caused by $T_{a}$ in the HQ mode. The experimental results were introduced to illustrate the effectiveness of the proposed approach. The advantage of this paper is that it has developed a tuning methodology and procedure of the $\mathrm{CNC}$ parameters based on their relevant machining mode required; it can easily be implemented in a commercial CNC controller of the machine tools. The machine user can simply select the best machining mode according to the machining requirements.

Author Contributions: B.-F.Y. and J.-S.C. In itiated and developed the concepts related to this research work. B.-F.Y. performed the collected data for the designed experiment and analyzed the data. Both of them discussed the experimental results and developed the tuning methodology. B.-F.Y. wrote the paper draft under Chen's guidance. All authors discussed the results and commented on the manuscript. All authors have read and agreed to the published version of the manuscript.

Funding: The authors would like to thank the reviewers for their suggestions. This research was supported by Ministry of Science and Technology, Taiwan grant to MOST-108-2218-E-005-021-“Intelligent multi-axis machine tool technology for machining the advanced materials of the semiconductor and electronics industries".

Conflicts of Interest: The authors declare no conflict of interest.

\section{References}

1. Erkorkmaz, K. High Speed Contouring Control for Machine Tool Drives. Master's Thesis, The University of British Columbia, Vancouver, BC, Canada, February 1999.

2. Erkorkmaz, K.; Altintas, Y. High speed CNC system design. Part I: Jerk limited trajectory generation and quantic spline interpolation. Int. J. Mach. Tools Manuf. 2001, 41, 1323-1345. [CrossRef]

3. Nam, S.-H.; Yang, M.-Y. A study on a generalized parametric interpolator with real-time jack-limited acceleration. Comput. Aided Des. 2004, 36, 27-36. [CrossRef]

4. Barre, P.-J.; Bearee, R.; Borne, P.; Dumetz, E. In fluence of a Jerk Controlled Movement Law on Vibratory Behaviour of High-Dynamics Systems. J. In tell. Robot. Syst. 2005, 42, 275-293. [CrossRef]

5. Lin, M.-T.; Tsai, M.-S.; Yau, H.-T. Development of a dynamics-based NURBS interpolator with real-time look-ahead algorithm. Int. J. Mach. Tools Manuf. 2007, 47, 2246-2262. [CrossRef]

6. Yau, H.-T.; Wang, J.-B. Fast Bazier interpolator with real-time lookahead function for high-accuracy machining. Int. J. Mach. Tools Manuf. 2007, 47, 1518-1529. [CrossRef] 
7. Sencer, B.; Altintas, Y.; Croft, E. Feed optimization for five-axis CNC machine tools with drive constraints. Int. J. Mach. Tools Manuf. 2008, 48, 733-745. [CrossRef]

8. Tapie, L.; Mawussi, K.B.; Anselmetti, B. Circular tests for HSM machine tools: Bore machining application. Int. J. Mach. Tools Manuf. 2007, 47, 805-819. [CrossRef]

9. Pateloup, V.; Duc, E.; Ray, P. Corner optimization for pocket machining. Int. J. Mach. Tools Manuf. 2004, 44, 1343-1353. [CrossRef]

10. Andolfatto, L.; Lavernhe, S.; Mayer, J.R.R. Evaluation of servo, geometric and dynamic error sources on five-axis high-speed machine tool. Int. J. Mach. Tools Manuf. 2011, 51, 787-796. [CrossRef]

11. Lee, K.; Ibaraki, S.; Matsubara, A.; Kakino, Y.; Suzuki, Y.; Arai, S.; Braasch, J. A Servo Parameter Tuning Method for High-Speed NC Machine Tools based on Contouring Error Measurement. In Laser Metrology and Machine Performance VI; WIT Press: Southampton, UK, 2002.

12. Parenti, P.; Bianchi, G.; Cau, N.; Albertelli, P.; Monno, M. A Mechatronic Study on a Model-Based Compensation of Inertial Vibration in a High-Speed Machine Tool. J. Mach. Eng. 2011, 11, 91-104.

13. Bringmann, B.; Maglie, P. A method for direct evaluation of the dynamic 3D path accuracy of NC machine tools. CIRP Ann. 2009, 58, 343-346. [CrossRef]

14. Li, B.; Luo, B.; Mao, X.; Cai, H.; Peng, F.; Liu, H. A new approach to identifying the dynamic behaviour of CNC machine tools with respect to different worktable feed speeds. Int. J. Mach. Tools Manuf. 2013, 72, $73-84$. [CrossRef]

15. Franco, P.; Estrems, M.; Faura, F. In fluence of radial and axial runouts on surface roughness in face milling with round insert cutting tools. Int. J. Mach. Tools Manuf. 2004, 44, 1555-1565. [CrossRef]

16. Buj-Corral, P.; Vivancos-Calvet, V.; González-Rojas, H. Roughness variation caused by grinding errors of cutting edges in side milling. Mach. Sci. Technol. 2013, 17, 575-592. [CrossRef]

17. Vivancos-Calvet, S.; Wiackiewicz, M.; Krolczyk, G.M. Study on metrological relations between instant tool displacements and surface roughness during precise ball end milling. Measurement 2018, 129, 686-694.

18. Mia, M.; Królczyk, G.; Maruda, R.; Wojciechowski, S. In telligent Optimization of Hard-Turning Parameters Using Evolutionary Algorithms for Smart Manufacturing. Materials 2019, 12, 879. [CrossRef]

19. Li, K.-Y.; Luo, W.-J.; Yang, M.-H.; Hong, X.-H.; Luo, S.-J.; Chen, C.-H. Effect of Supply Cooling Oil Temperature in Structural Cooling Channels on the Positioning Accuracy of Machine Tools. J. Mech. 2019, 35, 887-900. [CrossRef]

20. Li, K.-Y.; Luo, W.-J.; Huang, J.-Z.; Chan, Y.-C.; Pratikto; Faridah, D. Operational Temperature Effect on Positioning Accuracy of a Single-Axial Moving Carrier. Appl. Sci. 2017, 7, 420. [CrossRef]

21. Altintas, Y.; Verl, A.; Brecher, C.; Uriarte, L.; Pritschow, G. Machine tool feed drives. CIRP Ann. 2011, 60, 779-796. [CrossRef]

22. Altintas, Y. Virtual Machine Tool. CIRP Ann. 2005, 54, 115-138. [CrossRef]

23. Erkorkmaz, K.; Altintas, Y.; Yeung, C.-H. Virtual computer numerical control system. CIRP Ann. 2006, 55, 399-402. [CrossRef]

24. Lin, C.-Y.; Lee, C.-H. Remote Servo Tuning System for Multi-Axis CNC Machine Tools Using a Virtual Machine Tool Approach. Appl. Sci. 2017, 7, 776. [CrossRef]

25. Christian, B.; Fey, M.; Baumler, S. Damping models for machine tool components of linear axes. CIRP Ann. Manuf. Technol. 2013, 62, 399-402.

26. Zaeh, M.F.; Baudisch, T. Simulation environment for designing the dynamic motion behaviour of the mechatronic system machine tool. Proc. In st. Mech. Eng. Part B J. Eng. Manuf. 2003, 217, 1031-1035. [CrossRef]

27. Heidenhain. Technical Manual iTNC530 HSCI; Heidenhain: Traunreut, Germany, 2011.

28. Siemens. SINUMERIK 840D sl Basic Functions-Function Manual. Siemens AG, Germany. 2013. Available online: https://support.industry.siemens.com/cs/document/109763231/sinumerik-840d-sl-basicfunctions?dti=0\&lc=en-WW (accessed on 13 April 2020).

(C) 2020 by the authors. Licensee MDPI, Basel, Switzerland. This article is an open access article distributed under the terms and conditions of the Creative Commons Attribution (CC BY) license (http://creativecommons.org/licenses/by/4.0/). 